\title{
Wide Scale Characterization and Modeling of the Vibration and Damping Behavior of CFRP-Elastomer-Metal Laminates-Comparison and Discussion of Different Test Setups
}

\author{
Vincent Sessner ${ }^{1} \cdot$ Wilfried V. Liebig $^{1}$ (D) . Alexander Jackstadt ${ }^{2} \cdot$ Dominik Schmid $^{3}$. \\ Tom Ehrig $^{4}$ - Klaudiusz Holeczek ${ }^{4}$ - Nils Gräbner ${ }^{3}$. Pawel Kostka ${ }^{4}$. Utz von Wagner ${ }^{3}$. \\ Kay A. Weidenmann ${ }^{5}$. Luise Kärger ${ }^{2}$
}

Received: 4 September 2020 / Accepted: 5 April 2021 / Published online: 31 July 2021

(c) The Author(s) 2021

\begin{abstract}
The investigated hybrid carbon fiber reinforced plastics-elastomer-metal laminates (HyCEML) offer the potential of tailored structural materials with adaptable damping properties. Conventional fiber metal laminates, like glass laminate aluminum reinforced epoxy are already widely spread in the aviation industry owing to their outstanding fatigue behavior. By integrating an elastomeric interlayer, the glass fibers can be substituted by carbon fibers and damping properties of these laminates can be adjusted. The viscoelastic interlayer dissipates energy within the laminate by inducing shear strain during bending, which is commonly known as constrained layer damping. The aim of this paper is the description of the vibration and damping behavior of HyCEML over a wide temperature and frequency range by using different test methods. Dynamic mechanical analysis is used for the individual polymeric constituents and coupon specimens and modal analysis is used with different specimen geometries up to a component sized panel. In addition, analytical and numerical approaches complement the experiments and lead to a deeper understanding of the vibration and damping behavior. Owing to the high damping, already at frequencies of $5 \mathrm{kHz}$ only running waves can be detected for the investigated panel size. The discussion of different test methods helps to identify material and wavelength dependent effects, but also possible adverse effects of certain methods.
\end{abstract}

Keywords Hybrid · Constrained layer damping - Modal analysis · Dynamic mechanical analysis · Finite element analysis

Wilfried V. Liebig

wilfried.liebig@kit.edu

Extended author information available on the last page of the article 


\section{Introduction}

Due to the constantly increasing use of lightweight structures, there is also a permanent interest in the development and understanding of corresponding lightweight materials. Since lightweight structures are often prone to vibrations, the damping properties of the materials used are of great interest. A well-known and efficient damping mechanism, which is based on the viscoelastic behavior of polymers, is called constrained layer damping (CLD) [1]. The damping layer is subjected to comparably large shear deformation during a bending vibration, which results in a weight efficient damping behavior of this hybrid laminate. The principle is used in multiple applications in various technical fields such as the aerospace, railroad or automotive industries [2-4]. An analytical model for the description of the damping behavior of a three layered laminate has been presented by Ross et al. [5] and is often referred to as the Ross, Kerwin \& Ungar (RKU) equation. Up to now, this model has often been used and has also been extended for more complicated laminates with multiple viscoelastic layers [6].

The laminates studied in this investigation also damp according to this principle. Constraining layers made of alternating carbon fiber reinforced plastic (CFRP) and aluminum layers are separated by an elastomeric damping layer. This results in a hybrid CFRP-elastomer-metal laminate (HyCEML). HyCEML is based on the so-called fiber metal laminates (FML), which are mainly used in aviation due to their damage-tolerant behavior [7]. Compared to conventional FML, the additional isolating elastomer layer also allows the use of carbon fibers, which would otherwise lead to galvanic corrosion and thermally induced residual stresses in contact with the aluminum $[8,9]$. The carbon fibers also have the advantage of better mechanical properties compared to glass laminate aluminum reinforced epoxy (GLARE). In addition, the elastomer layer leads to a damping behavior according to the CLD mechanism. Due to the inhomogeneous layered structure, the loss factor in a CLD laminate depends on the wavelength of the bending waves [10]. For an analytical description of the damping behavior, an effective and constant sinusoidal wavelength is assumed in the RKU equation to model the damping behavior $[6,11]$. For the characterization of such laminate experimental modal analysis is usually applied where a modal loss factor can be associated with a specific mode of vibration and wavelength (twice the distance between two nodes). A standardized method for the characterization of the viscoelastic damping layer in a CLD laminate using a cantilever setup in a modal analysis also exists [12]. Nevertheless, many other studies have dealt with the optimization of the modal approach to improve the validity of the results [13-15]. Although the application of modal analyses has the advantage of being able to characterize the behavior in a mode-specific way, this results in the overlapping of effects of the frequency-dependent material behavior and the mode-specific CLD behavior. In order to separate these effects, a constant deformation must be applied, as it can be done with a non-resonant dynamic mechanical analysis (DMA). Usually, DMA is used to characterize the temperature and frequency dependent complex modulus of homogeneous materials. For polymers, the time-temperature-superposition (TTS) is often used to describe the material behavior beyond the experimental frequency range by generating so-called master curves [16]. Although DMA has been used to characterize viscoelastic damping layers applied in CLD applications [17], hybrid laminates as a whole are rarely characterized using this method [18, 19]. In addition, using different characterization methods and specimen geometries on the same laminate has rarely been done in the literature, although different methods can cover broader frequency ranges and different damping mechanisms. With different test methods, different types of loss factors are determined. However, for small loss factors these values can be transformed into each other [20]. This allows the results 
from different test methods to be compared with each other. Therefore, in the present study, the investigated HyCEML lay-up is not varied, but different test setups are used to characterize the damping phenomena and their influence on the damping behavior of such laminate.

Material data of the neat elastomer is investigated using DMA. Subsequently, the purely frequency-dependent behavior of the damping layer is mapped with the aid of master curves. For this purpose, tests on the elastomer under torsion are carried out at the Technische Universität Dresden, Institute of Lightweight Engineering and Polymer Technology (TUD ILK) and tests under tension are carried out at the Karlsruhe Institute of Technology, Institute for Applied Materials (KIT IAM). Thus, the transferability of the two complex modules between tension and torsion is to be verified. The data serves as input data for a conventional numerical model, applied by Karlsruhe Institute of Technology, Institute of Vehicle System Technology (KIT FAST). In addition, an analytical model according to the RKU equations [5] is applied by KIT IAM. The models are compared to the experimental results of the HyCEML under various test setups. To investigate the frequency and temperature dependence of HyCEML, DMA under bending are performed by KIT IAM. Thus, the damping behavior can be characterized under constant deformation and the TTS is used to describe the behavior at frequencies above and below the experimental test range. These results are compared to modal analyses in a cantilever beam geometry carried out by KIT IAM, as well as modal analyses on coupon specimens and a panel geometry with freefree supports carried out by the Technische Universität Berlin, Department of Applied Mechanics, Chair of Mechatronics and Machine Dynamics (TUB MMD). This shows the different effects of the pure viscoelastic material behavior and the wavelength dependent CLD mechanism. Finally, the wave propagation above the resonant range is investigated by the TUD ILK to complete the wide scale characterization from the sub-resonant over the resonant, to the super-resonant range.

The comparison of viscoelastic master curves of hybrid CLD laminates with results from modal analysis has not yet been performed in the literature and helps to show the influence of different damping effects. In addition, the correlation of the results from different test methods with an analytical and a numerical model is used to identify possible adverse effects of certain methods and assumptions. Although the models used in our study cannot cover all damping effects, which results in deviations between experimental, numerical and analytical results, they can help to understand and apply the damping phenomena resulting from different mechanisms.

\section{Materials}

\subsection{Hybrid CFRP-Elastomer-Metal-Laminates (HyCEML)}

HyCEML consist of common CFRP prepreg material HexPly® M77/38\%/UD150 CHS12 K-T700 (provided by Hexcel Corporation), elastomer (El) Kraibon® SAA9579-52 (provided by Gummiwerk Kraiburg GmbH \& Co. KG) and aluminum alloy (Al) AL2024-T3 AlCLAD sheets (provided by Kastens Knauer $\mathrm{GmbH}$ ). The laminate is laid-up in the form of CFRP-El-Al-El-CFRP, where CFRP layers are stacked as [0/90], as shown in Fig. 1.

The panel is manufactured in a hot molding process and is consolidated for $300 \mathrm{~s}$ by applying a pressure of $40 \mathrm{bar}$ at a temperature of $150{ }^{\circ} \mathrm{C}$ as recommended by the manufacturers of the CFRP prepreg and elastomer. Prior to consolidation, the aluminum sheets are cleaned with acetone. No additional preliminary work had to be carried out on the 
Fig. 1 Cross section of a symmetric hybrid CFRP-elastomermetal laminate

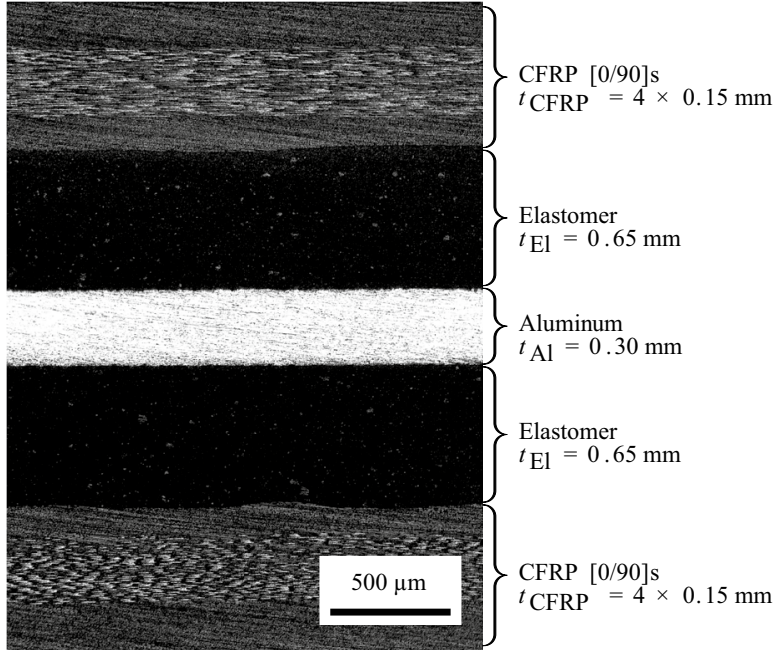

elastomer and the CFRP sheets. Since both the elastomer and the CFRP cure under high pressure during consolidation, an ideal interface is assumed without additional frictional losses. The good adhesion properties have also been shown in previous studies [21]. Consequently, the damping results only from the viscoelastic material behavior of the constituents. The original panel size is $400 \mathrm{~mm} \times 400 \mathrm{~mm}$ with a thickness of $2.8 \mathrm{~mm}$, such that a panel $(380 \mathrm{~mm} \times 380 \mathrm{~mm})$ can be cut out for vibration and damping analyses. For further measurements, coupon specimens $(l \times w=250 \mathrm{~mm} \times 15 \mathrm{~mm}, l \times w=125 \mathrm{~mm} \times 15 \mathrm{~mm}$ and $l \times w=125 \mathrm{~mm} \times 30 \mathrm{~mm}$ ) are cut by water jet cutting in such a way, that the fibers of the outer CFRP layer are oriented along the long side of the coupon specimens.

\subsection{Quasistatic Properties of HyCEML Constituents}

Mechanical properties of the CFRP are summarized in Table 1. The listed properties are measured by performing tensile tests of unidirectional CFRP coupon specimens with $0^{\circ}$ and $90^{\circ}$ fiber orientation according to EN ISO 527 [22] and tensile tests on $\pm 45^{\circ}$ laminates according to DIN EN 6031 [23]. The modulus values are determined in a strain range of $0.05 \%$ to $0.25 \%$ as stated in the aforementioned standards. This data is used for the analytical model described in Sect. 3.3.

For all studies an ethylene propylene diene monomer (EPDM) elastomer (Kraibon ${ }^{\circledR}$ SAA9579-52) is utilized as the interlayer between CFRP and aluminum with optimized adhesion to both materials. It is provided as an uncured elastomer foil whose polymer chains cross-link during the consolidation process. The cured ply thickness of the elastomer is $t_{\mathrm{El}}=0.65 \mathrm{~mm}$ according to its data sheet. The quasistatic mechanical material properties of the elastomer are measured by tensile tests based on ISO 37 [24] and are given in Table 2. The aluminum sheet (AL2024-T3 AlCLAD) has a thickness of $t_{\mathrm{Al}}=0.3 \mathrm{~mm}$. All mechanical properties are also summarized in Table 2 and are based on a data sheet from the manufacturer. 
Table 1 Elastic material properties of CFRP M77/CHS

\begin{tabular}{lll}
\hline Fiber orientation & Young's modulus & Density \\
\hline$/ \circ$ & $E / \mathrm{GPa}$ & $\rho / \mathrm{kg} / \mathrm{m}^{3}$ \\
0 & 103.7 & \\
90 & 7.75 & 1496 \\
45 & 15.1 & \\
\hline
\end{tabular}

\section{Methods}

\subsection{Dynamic Mechanical Analysis of HyCEML Constituents}

DMA are carried out to study the viscoelastic material behavior of the elastomer in order to gain material data for the analytical model (Sec. 3.3) and the numerical simulations (Sec. 3.4). Experiments are performed according to ISO 6721-4 [25] in tension on the CFRP as well as on the elastomer and according to ISO 6721-7 [26] in shear mode on the elastomer. This allows the measurement of the temperature and frequency dependent loss modulus $G^{\prime \prime}$ and storage modulus $G^{\prime}$ and their ratio defined as the loss factor $\tan \delta=G^{\prime \prime} / G^{\prime}$. Results of the DMA on the neat CFRP are not part of this study but are published by Liebig et al. [27], which are used for the numerical model. Tests of both load states (tension and shear) of the elastomer are taken to verify the convertibility of the results from one load state into the other by approximating incompressibility of the elastomer $(\nu=0.48)$, e.g. the shear modulus of the isotropic material $G=E /(2(1+\nu))$ is approximately one third of Young's modulus [28].

The DMA experiment in shear mode is carried out by using a MCR 502 Rheometer (Co. Anton Paar) equipped with a CTD 450 convection temperature device. The test setup is shown in Fig. 2 on the left. To perform the tests, a solid rectangular fixture measuring system (SRF) is used and the elastomeric coupon specimens $(l \times w \times t=40 \mathrm{~mm} \times 10 \mathrm{~mm} \times$ $2 \mathrm{~mm}$ ) are loaded within their linear-elastic regime. Owing to a clamping length of $7 \mathrm{~mm}$ on both sides, a gauge length of $l_{0}=26 \mathrm{~mm}$ is used to determine the dynamic mechanical properties. Spacers are used for an accurate positioning and centering of the coupon specimens. The lower clamp is rigidly connected to the rheometer while the upper clamp oscillates. For each temperature step (temperature range: $-80{ }^{\circ} \mathrm{C}$ to $56{ }^{\circ} \mathrm{C}$; temperature step increment: $\left.3{ }^{\circ} \mathrm{C}\right)$, the coupon specimen is tested at five different frequencies $(0.1 \mathrm{~Hz}$, $0.316 \mathrm{~Hz}, 1 \mathrm{~Hz}, 3.16 \mathrm{~Hz}$ and $10 \mathrm{~Hz}$ ) by applying an amplitude of the twisting angle which is equivalent to a maximum strain amplitude of $0.5 \%$. The shear deformation is applied in fully reversed mode resulting in a peak-to-peak value of $1 \%$ strain. For testing, the coupon specimen is preloaded by a tension force of $0.2 \mathrm{~N}$ to prevent bending.

The DMA experiment in tension-tension mode is carried out on an Instron ElectroPuls E3000 testing machine equipped with a climate chamber. The test setup is shown

Table 2 Elastic material properties of the elastomer $\left(t_{\mathrm{El}}=0.65 \mathrm{~mm}\right)$ and aluminum $\left(t_{\mathrm{Al}}=0.3 \mathrm{~mm}\right)$

\begin{tabular}{llll}
\hline Type & $\begin{array}{l}\text { Young's modu- } \\
\text { lus } E / G P a\end{array}$ & $\begin{array}{l}\text { Poisson's } \\
\text { ratio } v /-\end{array}$ & Density $\rho / \mathrm{kg} / \mathrm{m}^{3}$ \\
\hline SAA9579-52 & 0.045 & 0.4800 & $1180^{*}$ \\
AL2024-T3 & $73.10^{*}$ & $0.3054^{*}$ & $2760^{*}$ \\
\hline
\end{tabular}

* values from data sheet 
Fig. 2 Test setup for DMA in torsion (left) and tension (right) on the elastomer

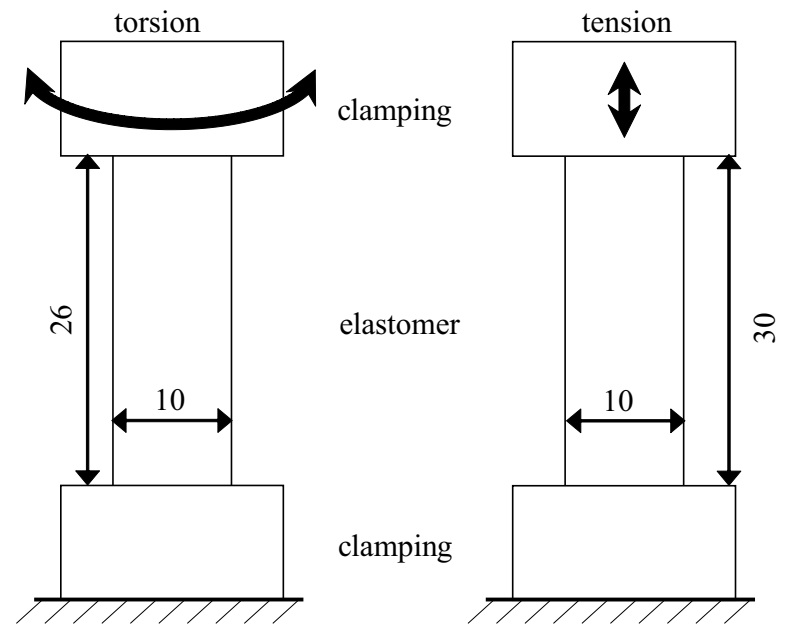

in Fig. 2 on the right. Elastomeric coupon specimens with dimensions of $(l \times w \times t=$ $100 \mathrm{~mm} \times 10 \mathrm{~mm} \times 2 \mathrm{~mm}$ ), taken from the same batch material as for the shear characterization, are used. The gauge length of the coupon specimen in the fixture is set to $l_{0}=30 \mathrm{~mm}$. The experiment is strain-controlled with a maximum strain of $1 \%$ by applying an amplitude of $0.33 \%$ at a middle deflection of $0.66 \%$. Slightly different strain ranges are unavoidable due to the different test methods in tension and shear (tensionstension / tension-compression). The tested temperature range is $-80{ }^{\circ} \mathrm{C}$ to $80{ }^{\circ} \mathrm{C}$ (temperature step increment: $2.5^{\circ} \mathrm{C}$ ) with the same frequencies as in shear mode. The master curves are obtained by applying the TTS at a chosen reference temperature $\left(T_{\text {ref }}=-52.7^{\circ} \mathrm{C}\right)$, according to Eq. (1) [29]:

$$
\log _{10}\left(\alpha_{T}\right)=\frac{-c_{1}\left(T-T_{r e f}\right)}{c_{2}+\left(T-T_{r e f}\right)} .
$$

Horizontal shift factors $a_{\mathrm{T}}$ are determined from the rheometer measurements to shift the data to the reference temperature. The shift factors were determined by fitting each isothermal frequency sweep with a polynomial of third degree. Adjacent fits are shifted horizontally on the logarithmic frequency scale (reduced frequency), so that the quadratic deviation from the neighboring polynomials is minimal on the average. Thus, the coefficients $c_{1}$ and $c_{2}$ are determined from a curve fitting to be 21.33 and $86.54{ }^{\circ} \mathrm{C}$, respectively. The same shift factors are used for the data from tensile and shear DMA of the elastomer, as the determined values of the shift function on the tension data shows very good accordance with the data from the shear measurement. The results can be seen in Fig. $3 \mathrm{a}$ as the normalized modulus for a reference temperature of $-52.7^{\circ} \mathrm{C}\left(E^{\prime \prime}\right.$ peak at $1 \mathrm{~Hz}$ ) and in b) as the actual values of storage and loss modulus and loss factor at a reference temperature of $20{ }^{\circ} \mathrm{C}$. These shift factors provide smooth master curves for both DMA measurement modes, as can be seen in Fig. 3a. The results show the same behavior for both modes with a slightly vertical shift.

Amplitude dependence in DMA of elastomers is known by the so-called Payne effect, which results in a lower modulus at higher strain amplitudes [30]. The static pre strain of the tension DMA is believed to have no influence on the Payne effect [31]. Hence, the higher strain amplitude in the shear DMA would result in a lower modulus, which is not 
the case in our study. Therefore, the lower modulus in the tension DMA might be due to the higher maximum strain in the tension mode as a result of the hyperelastic material behavior but not due to the Payne effect. Also a cyclic stress softening due to the Mullins effect [32] might explain the lower modulus in tension mode. However, a detailed investigation of this effect is beyond the scope of this investigation.

\subsection{Damping Characterization of HyCEML}

\subsubsection{Three Point Bending Dynamic Mechanical Analysis}

Since the aim of this paper is the characterization of the damping behavior of the hybrid laminate, beside the experimental DMA on the polymeric constituents, a three point bending (3PB) DMA is conducted on an unclamped HyCEML coupon specimen $(125 \mathrm{~mm} \times 15 \mathrm{~mm})$. Therefore, the testing machine Instron E3000 is equipped with a three point bending setup, at which the support span is set to $80 \mathrm{~mm}$. The test setup is shown in Fig. 4. The loading is deflection controlled in compression mode with a middle deflection of $0.2 \mathrm{~mm}$ and an amplitude of $0.075 \mathrm{~mm}$. Temperature steps of $2.5{ }^{\circ} \mathrm{C}$ are chosen in the range of $-70{ }^{\circ} \mathrm{C}$ to $-25{ }^{\circ} \mathrm{C}$ and $5{ }^{\circ} \mathrm{C}$ in the range of $-25{ }^{\circ} \mathrm{C}$ to $200{ }^{\circ} \mathrm{C}$, respectively. The same frequencies from $0.1 \mathrm{~Hz}$ to $10 \mathrm{~Hz}$ in five logarithmic steps as in Sec. 3.1 are applied. The results are used to determine a master curve from the frequency and temperature measurements by using the TTS approach as described before. The shift factors are calculated by horizontally shifting the storage modulus curves to gain the best fitting continuation of the surrounding curves as described in [33]. To characterize the damping behavior, the system's loss factor $\tan \delta$ for forced bending vibrations is defined as the ratio of the homogenized loss to storage modulus. Since in the 3PB experiment the specimen is always deformed in the same way, defined by the support distance and deflection amplitude, this experiment is particularly suitable to investigate the temperature and frequency dependence without the influence of the mode shape.

a)

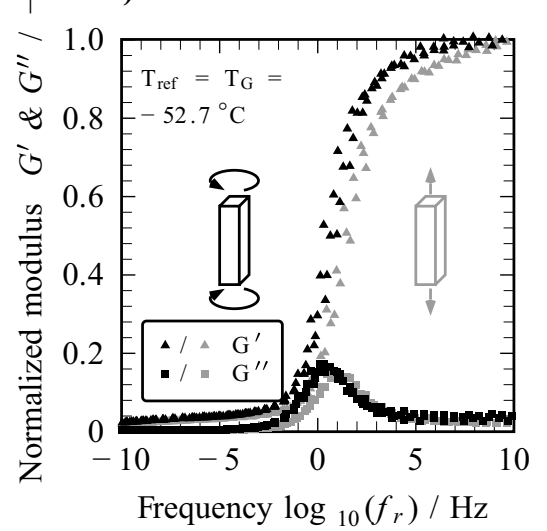

b)

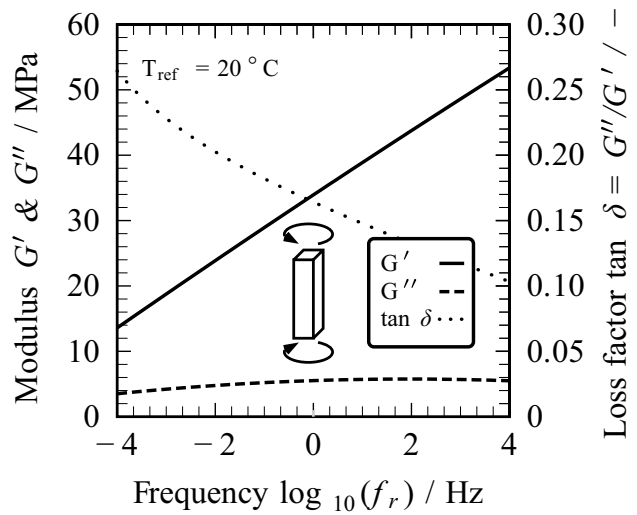

Fig. 3 a) Normalized master curves of storage modulus $G^{\prime}$ and loss modulus $G^{\prime \prime}$ against reduced frequency $f r$ of the elastomer at a temperature of $T_{\text {ref }}=T_{\mathrm{G}}=-52.7^{\circ} \mathrm{C}$ determined from DMA measurements in tension (storage modulus $G^{\prime}$ and loss modulus $G^{\prime \prime}$ determined from $G \approx E / 3$ ) and torsional shear mode. b) Fit curve, in an experimentally relevant frequency range of $10^{-4} \mathrm{~Hz}$ to $10^{4} \mathrm{~Hz}$, derived from DMA master curve and shifted to $T=20^{\circ} \mathrm{C}$ 


\subsubsection{Modal Analysis with Cantilever Beam Experiment and Sweep Excitation}

The cantilever beam method according to ASTM E756-05 [12] is carried out on coupon specimens with dimensions of $(250 \mathrm{~mm} \times 15 \mathrm{~mm})$ and is schematically shown in Fig. 5a. The tests are conducted at room temperature. The specimen is clamped with a free length of $210 \mathrm{~mm}$. The excitation is realized with an electromagnetic non-contact method, by a coil and a harmonic frequency sweep of $10 \mathrm{~Hz}$ to $6000 \mathrm{~Hz}$ to capture the first and higher bending mode shapes within this frequency range. The number of natural frequencies that can be detected also depends on the sensitivity and placement of the vibration measuring sensor. The limited sensitivity of the capacitive sensor can therefore result in a reduced frequency range in which natural frequencies can be detected. As the materials used in the HyCEML are non-ferromagnetic, a small magnet is glued onto one side of the specimen for excitation. The cylindrical magnet has a diameter of $3 \mathrm{~mm}$ and a thickness of $1 \mathrm{~mm}$ which results in a mass of about $53 \mathrm{mg}$. This is less than $1 \%$ of the mass of the specimens free length and should not lead to large errors in the damping measurement [34]. This has also been verified by the authors in finite element method (FEM) simulations of the experimental setup with and without the added mass of the magnet. The excitation force is measured as the reaction force on the coil with a force transducer (Dytran 1051V1) at the free end. The displacement of the specimens is measured with a contactless capacitive displacement sensor (E+H, AW 210-22-1) in its linear measuring range, at a distance of $25 \mathrm{~mm}$ from the clamping. This represents one of the possible exciter / response transducer arrangements according to the standard [12]. The frequency response function (FRF) is determined and the half power bandwidth method is used to calculate the loss factor $\eta$ in the natural frequencies [20]. 12,000 FFT lines in the frequency range of $0 \mathrm{kHz}$ to $6 \mathrm{kHz}$ are used for determination of the FRF with a rectangle window function and the average of three measurements for each specimen. Three specimens are measured in this configuration.

\subsubsection{Modal Analysis with Free Boundaries and Pulse Excitation}

To investigate the influence of the specimen geometry and to study the characteristics of larger components experimental modal analysis as shown in Fig. 5b, c and d is carried out on a panel and coupon specimens with different dimensions. For this purpose, the squared panel $(380 \mathrm{~mm} \times 380 \mathrm{~mm})$ and coupon specimens $(125 \mathrm{~mm} \times 30 \mathrm{~mm}$ and $125 \mathrm{~mm} \times 15 \mathrm{~mm})$

Fig. 4 Sketch of test setup for 3PB DMA on HyCEML

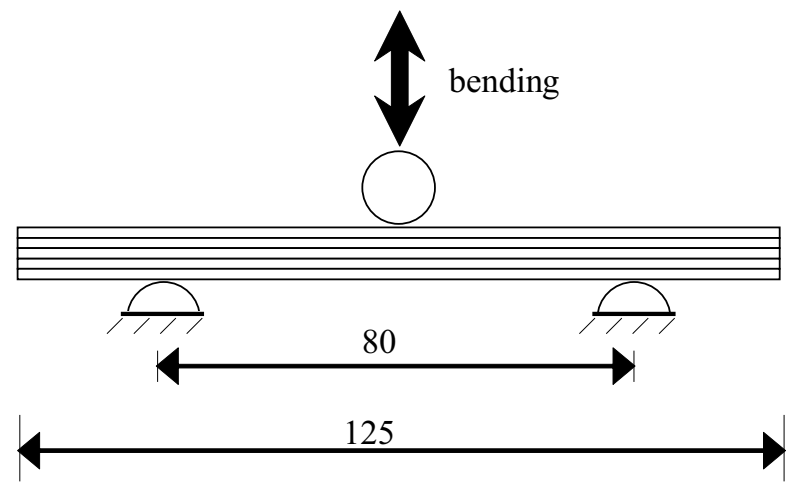


a)

Cantilever specimen $(210 \mathrm{~mm} \times 15 \mathrm{~mm})$

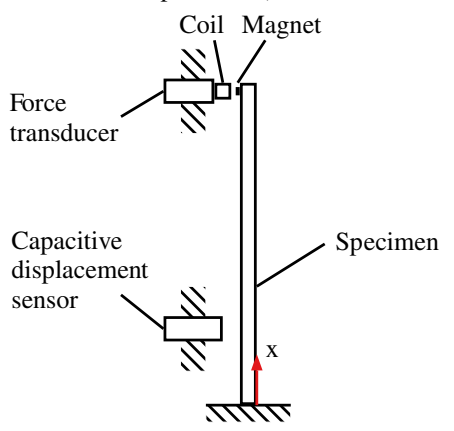

c) Coupon specimen $(125 \mathrm{~mm} \times 30 \mathrm{~mm})$

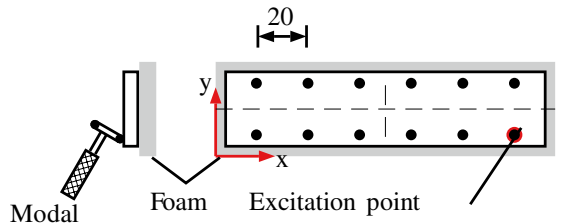

Modal

hammer b)

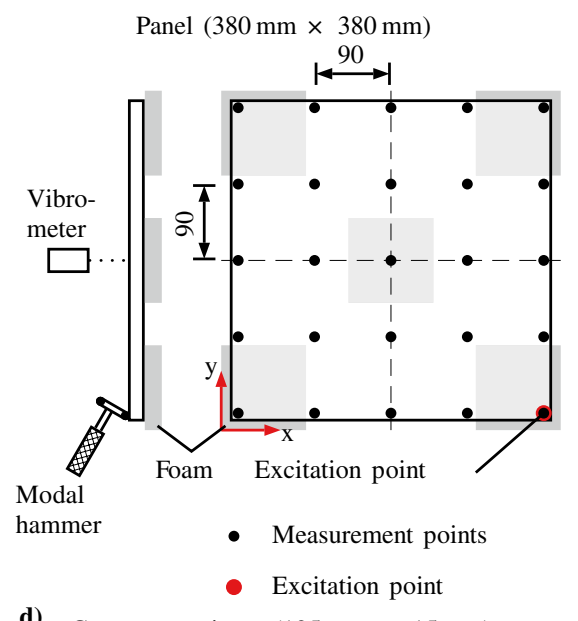

d) Coupon specimen $(125 \mathrm{~mm} \times 15 \mathrm{~mm})$

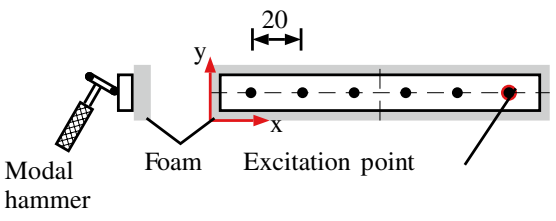

Fig. 5 Sketch of test setup for modal analysis on a) cantilever specimen $250 \mathrm{~mm} \times 15 \mathrm{~mm}$ clamped with a free length of $210 \mathrm{~mm}$; b) panel: $380 \mathrm{~mm} \times 380 \mathrm{~mm}$; c) coupon specimen: $125 \mathrm{~mm} \times 30 \mathrm{~mm}$; d): coupon specimen $125 \mathrm{~mm} \times 15 \mathrm{~mm}$; Excitation and measurement points are shown for all specimens. For all setups, the outer fibers of the specimens are oriented along the $\mathrm{x}$-direction

cut out of the panel are used. The panel and the coupon specimens are placed on a soft foam (representing free boundary conditions on all sides) and are excited by using an automatic modal hammer (Maul-Theet, vImpact-60). Thus, force levels of approximately $20 \mathrm{~N}$ to $50 \mathrm{~N}$ can be reached. To measure the velocity in out-of-plane direction of the examined panel or coupon specimens, respectively, a single point laser Doppler vibrometer (Optomet, Nova Basis) is used which is positioned perpendicular to the surface of the analyzed panel / coupon specimen. The contactless measurement avoids any influence of the sensors on the mode shapes and natural frequencies. Two rectangular coupon specimens are investigated for each width and one specimen for the panel geometry. The tests are conducted at room temperature.

For the examination, 25 measuring points are applied on the panel, six on the $15 \mathrm{~mm}$ wide and twelve measuring points on the $30 \mathrm{~mm}$ wide coupon specimens. The number of measuring points and the excitation points are chosen to capture higher mode shapes. The FRF of each point is determined as an average of five measurements for the panel and ten for the specimens. 1600 FFT lines are used in the range of $0 \mathrm{kHz}$ to $5 \mathrm{kHz}$. Rectangle windows are used in the FFT. For the determination of natural frequencies, damping ratios and mode shapes, the FRF of each measurement point is analyzed. A multi-degree-of-freedom method (MDOF), which considers the coupling of mode shapes and determines damping ratios and natural frequencies resulting from curve fitting is applied. Here the damping 
ratio $\vartheta$ describes the energy dissipation behavior of each mode shape [35]. Note, that the half power value bandwidth $\eta$ is approximately twice the size of the experimental determined damping ratio $\vartheta$. For the loss factor it is reasonable to assume $\eta=2 \vartheta=\tan \delta$ for small loss factors $\eta \ll 1[20,36]$. This relation is used to compare the results from DMA and modal analysis.

\subsubsection{Wave Attenuation Analysis}

The modal analysis of a strongly damped structure becomes less meaningful in a higher frequency range since the excited waves reach the structure edges strongly attenuated and produce no distinct forms of vibration. Therefore, a characterization of the structural dynamic behavior in terms of running waves instead of mode shapes and natural frequencies becomes more appropriate at higher frequencies. The analysis carried out should provide indications for the selection of the adequate method for a given HyCEML structure depending on its size and application-specific frequencies. The wave attenuation behavior is analyzed on the $380 \mathrm{~mm} \times 380 \mathrm{~mm}$ panel used in Sec. 3.2.3 for the modal analysis. Since contactless electromagnetic excitation (Sec. 3.2.2) and the modal hammer excitation (Sec. 3.2.3) are limited in energy input at high frequencies, a setup shown in Fig. 6 is used. The excitation in the middle of the panel is chosen to minimize the influence of reflected waves from the edges of the panel in the wave attenuation analysis. The vibration excitation is introduced by using a laboratory electrodynamic shaker (type 4809, Brüel \& Kjær) with a nominal excitation frequency range of $10 \mathrm{~Hz}$ to $20 \mathrm{kHz}$ and a maximum force amplitude of $45 \mathrm{~N}$. To measure the exerted force and the acceleration at the excitation point, an impedance head transducer (type 8001, Brüel \& Kjær) is used. It allows to record the vibrations in a frequency range between $0.001 \mathrm{~Hz}$ and $10 \mathrm{kHz}$ up to $20000 \mathrm{~ms}^{-2}$ and $300 \mathrm{~N}$ for acceleration and force, respectively. The velocity measurement in out-of-plane direction of the examined panel is conducted by using a scanning laser Doppler vibrometer (PSV-400, Polytec $\mathrm{GmbH}$ ). In order to assure a high reflection of the laser light and, hence a good signal-to-noise ratio, a section of the panel surface is covered by a self-adhesive reflective foil, as illustrated in Fig. 6. A forced excitation at a fixed frequency of $5 \mathrm{kHz}$ is applied and the vibration response is measured at 625 points uniformly distributed on the grey marked area in Fig. 6. The tests are performed at room temperature.

\subsection{Analytical RKU model}

The cantilever beam setup and the modal analysis on the coupon specimens is also modeled with an analytical approach according to the Ross, Kerwin \& Ungar (RKU) equations [5]. Under the assumption of $E_{2} \ll E_{1}$ and with the complex unit i, the homogenized complex bending stiffness $E I(1+i \eta)$ of the symmetrical five layer laminate can be written as [6]:

$$
E I(1+i \eta)=E_{1} I_{1}+2 E_{3} I_{3}+2 E_{3} H_{3} H_{31}^{2} \frac{g\left(1+i \eta_{2}\right)}{1+g\left(1+i \eta_{2}\right)}
$$


Fig. 6 Sketch of test setup for high frequency vibration analysis. The outer fibers of the specimens are oriented along the $\mathrm{x}$-direction

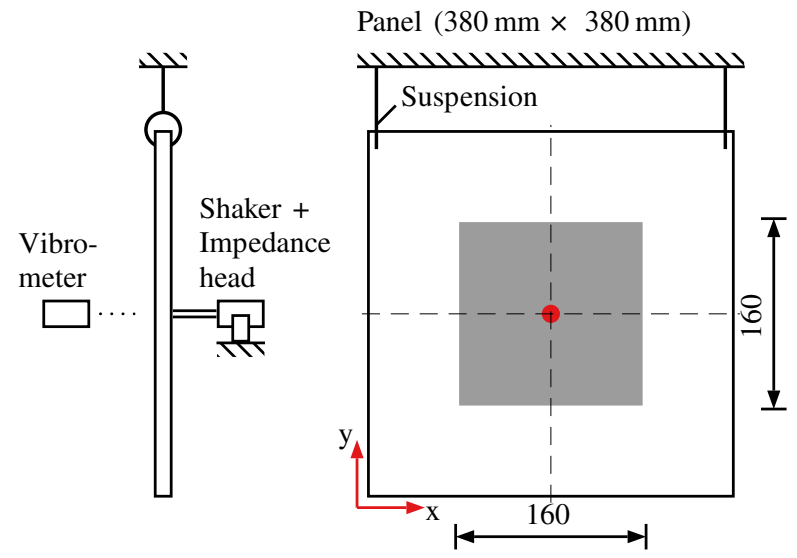

625 measurement points on reflective foil

- Excitation point

with

$$
\begin{gathered}
H_{31}=\frac{H_{1}+H_{3}}{2}+H_{2} \\
g=\frac{G_{2} L^{2}}{E_{3} H_{3} H_{2} \alpha_{n}} .
\end{gathered}
$$

Where $E, I, H$ are the Young's modulus, second moment of inertia and height of the layer. Index 1 refers to the aluminum layer, index 2 to the elastomer layers and index 3 to the CFRP layers. $L$ is the free length of the specimen. $G_{2}$ is the complex and frequency dependent shear modulus of the elastomer from the DMA master curve shown in Fig. $3 \mathrm{~b}$ in Sec. 3.1. The exact modulus value for each natural frequency is determined by iteration. The CFRP and aluminum layers are assumed to be isotropic and linear elastic non-damping in this approach. The Young's modulus of the [0/90] $]_{\mathrm{S}}$ CFRP layers is chosen as 55.7GPa, determined by a rule of mixture $\left(E^{0 / 90}=\left(E^{0}+E^{90}\right) * 0.5\right)$ from the data presented in Sec. 2.2 Table 1. The data for the aluminum is shown in Sec. 2.2 Table 2.

For clamped-free boundary conditions $a_{1}=3.516$ [37]. For $\mathrm{n}>1 a_{n}$ for the $n$-th bending mode shape is chosen as:

$$
\alpha_{n}=(2 n-1)^{2} \pi^{2} / 4
$$

For free-free boundary conditions and the $n$-th bending mode shape, $a_{n}$ is chosen as [6]:

$$
\alpha_{n}=(2 n+1)^{2} \pi^{2} / 4
$$

The semi wavelength of the $n$-th mode shape can be calculated according to [11]:

$$
\lambda_{n}=\frac{\pi L}{\sqrt{\alpha_{n}}} .
$$


The natural frequency of the $n$-th bending mode is determined with the homogenized modulus:

$$
f=\sqrt{\frac{E \alpha_{n}^{2} H^{2}}{48 \rho L^{4} \pi^{2}}} .
$$

\subsection{Numerical Studies}

In order to validate and compliment the experimental setup, numerical studies using the commercial finite element solver Abaqus are performed. The models are setup so that the laminate lay-ups and dimensions correspond to the ones listed in Sec. 3.2. Quadratic continuum elements C3D20 are used throughout the model. The number of elements used in each direction for the different specimen geometries is listed in Table 3. For the 3PB DMA each UD CFRP and aluminum layer is modeled with three elements and each elastomer layer is modeled with five elements in thickness direction. For the cantilever setup, both widths of the coupon specimens and the panel geometry each UD CFRP and aluminum layer is modeled with one element and each elastomer layer is modeled with three elements in thickness direction. A convergence study has shown that a further mesh refinement in thickness direction does not affect the resulting quantities of interest. Due to the computational effort, a coarser mesh was used for the panel. The validity of this mesh has also been confirmed in a mesh study by the authors. Ideal adhesion is assumed between the different layers. Interface characteristics are therefore not taken into account. A hybrid element formulation is chosen for the elastomeric layers to account for their incompressibility. The aluminum layers are modeled as linear elastic with the elastic properties and mass density listed in Table 2. The elastomer layers are considered to be viscoelastic corresponding to the complex shear modulus master curve shown in Fig. 3. Since all simulations are performed in the frequency domain, no further material model is needed, which marks a different approach than in previously published studies, in which Prony series were used [38]. The elastomer's mass density is taken from the manufacturer's data sheet and is listed in Table 2. Each unidirectional CFRP layer is modeled as a transversely isotropic viscoelastic material by using the material model and parameters introduced in [27] and the mass density listed in Table 1 . Thus, in contrast to the analytical model, the numerical model takes into account the anisotropic nature of the $[0 / 90]_{\mathrm{S}}$ laminate lay-up of the CFRP face sheets.

Table 3 Number of elements used in the numerical model for the HyCEML in each test setup

\begin{tabular}{llll}
\hline & \multicolumn{2}{l}{ Number of elements per direction } \\
\cline { 2 - 4 } & $\mathrm{x}$ & $\mathrm{y}$ & $\mathrm{z}$ \\
\hline 3PB DMA & 120 & 12 & 37 \\
Cantilever & 125 & 16 & 15 \\
Coupon (both widths) & 125 & 30 & 15 \\
Panel & 150 & 150 & 15 \\
\hline
\end{tabular}




\subsubsection{Three Point Bending DMA}

The 3PB DMA previously described in Sec. 3.2.1 is simulated by conducting a steady-state frequency sweep from $10^{-4} \mathrm{~Hz}$ to $10^{4} \mathrm{~Hz}$, but not exceeding the first natural frequency of the specimen. This allows for the consideration of the frequency dependent material behavior of the elastomer and CFRP. The specimen is, according to the experimental setup, first prescribed by a deflection of $u_{3}=0.2 \mathrm{~mm}$ and then excited with an amplitude $\Delta u_{3}=$ $0.075 \mathrm{~mm}$. The two supporting pins in the setup are modeled as rigid bodies according to the dimensions in the actual experiment. Contact between pin and specimen is considered frictionless. The complex bending modulus of the specimen is then determined from the complex reaction force $F_{3}{ }^{*}$ at the location of maximum deflection in the specimen, so that the corresponding loss factor is calculated as the ratio of imaginary and real part of $F_{3}{ }^{*}$,

$$
\tan \delta=\frac{\mathfrak{\mho}\left(F_{3}^{*}\right)}{\mathfrak{\Re}\left(F_{3}^{*}\right)} .
$$

The amplitudes of the bending stress $\Delta \sigma$ and strain $\Delta \varepsilon$ can then be determined from the loss factor $\tan \delta$ and the prescribed displacement amplitude $\Delta u_{3}$ :

$$
\begin{gathered}
\triangle \sigma=\frac{3 l\left|F_{3}^{*}\right|}{2 \omega t^{2}}\left(1+6 \frac{\triangle u_{3}^{2}}{l^{2}}-4 \frac{t}{l} \frac{\triangle u_{3}}{l}\right), \\
\triangle \varepsilon=6 \triangle u_{3} \frac{t}{l^{2}} .
\end{gathered}
$$

In Eqs. (10) and (11) $l$ denotes the free length of the specimen, $w$ the width and $t$ is the thickness. Due to the globally small deformations, a linear strain measure is used. The effective complex bending modulus of the laminate can then be calculated as

$$
E^{*}=\frac{\triangle \sigma}{\triangle \varepsilon}(\cos \delta+i \sin \delta)
$$

The same equations are used to evaluate the experimental 3PB DMA.

\subsubsection{Modal Analysis}

Furthermore, numerical complex modal analyses are conducted on the cantilever specimens illustrated in Sec. 3.2.2 and the coupon specimens and panel geometry shown in Sec. 3.2.3. The boundary conditions correspond to the ones shown in Fig. 5. The foam bedding, however, is neglected for a lack of material data. Since the frequency dependency of the material behavior cannot be considered in modal analysis, the constitutive models are evaluated only at a specific frequency. This evaluation frequency has been chosen based on the experimental findings so that it lies in the interval in which the modes of interest are to be expected. An evaluation frequency of $f_{\text {cantilever }}=1000 \mathrm{~Hz}$ is chosen for the cantilever beam setup. In case of the coupon specimen an evaluation frequency of $f_{\text {coupon }}=700 \mathrm{~Hz}$ is chosen whereas for the panel geometry a lower frequency of $f_{\text {plate }}=150 \mathrm{~Hz}$ is selected. 


\section{Experimental, Analytical and Numerical Results}

\subsection{Three Point Bending Dynamic Mechanical Analysis}

The experimentally determined, effective bending storage modulus and loss factor master curve of HyCEML is shown in Fig. 7 for a reference temperature of $-40{ }^{\circ} \mathrm{C}, 20^{\circ} \mathrm{C}$ and $80{ }^{\circ} \mathrm{C}$. It is obtained by applying the TTS principle as described in Sec. 4.1 to the three point bending DMA results, meaning the isothermal frequency sweeps are shifted by horizontal shift factors to form a continuous master curve. The procedure is also described in previous studies [33]. Additionally, the numerical results are shown in a frequency range of $10^{-4} \mathrm{~Hz}$ to $10^{2.8} \mathrm{~Hz}$ determined for a reference temperature of $20{ }^{\circ} \mathrm{C}$, in order to compare the general trend of the curves to the TTS approach. The upper limit marks the first natural frequency of the specimen. From this frequency on, an evaluation with a displacement controlled excitation does no longer make sense experimentally and numerically. The amplitude of the unclamped specimen can exceed that of the excitation and thus no reaction force can be measured. As the experimental master curve is determined by TTS, the behavior in this frequency range can be predicted using this method. The numerical simulation however, fails under the chosen setup.

The glass transitions of the elastomer and the CFRP are marked by the two peaks of the loss factor $\tan \delta$. For a reference temperature of $T_{\text {ref }}=20{ }^{\circ} \mathrm{C}$, a constant decreasing loss factor $\tan \delta$ in a frequency range of $10^{-4} \mathrm{~Hz}$ to $10^{4} \mathrm{~Hz}$ is determined from the measurements. This frequency range is chosen to cover most of the occurring vibrations in technical applications. When the reference temperature is chosen as $T_{\text {ref }}=-40{ }^{\circ} \mathrm{C}$, the axis of reduced frequency $\left(f_{r}\right)$ [39] is shifted to the right. At this temperature, the glass transition of the elastomer has strong influence on the loss factor $\tan \delta$ in the aforementioned frequency range. The same phenomenon occurs when the reference temperature is set to a higher value of $T_{\text {ref }}=80{ }^{\circ} \mathrm{C}$. Here, the glass transition of the CFRP influences the material damping but only below frequencies of $10^{-2} \mathrm{~Hz}$. It can also be seen that the experimental and numerical results show the same trend with increasing frequency. The numerical model predicts an $11 \%$ higher storage modulus for a frequency of $10^{-4} \mathrm{~Hz}$ and $12 \%$ higher for $10^{2.8} \mathrm{~Hz}$. The

Fig. 7 Experimental and numerical effective bending storage modulus and loss factor master curve for 3PB DMA at a reference temperature of $-40{ }^{\circ} \mathrm{C}$, $20{ }^{\circ} \mathrm{C}$ and $80{ }^{\circ} \mathrm{C}$ on a coupon specimen $(125 \mathrm{~mm} \times 15 \mathrm{~mm})$. Numerical results are determined in a frequency range of $10^{-4} \mathrm{~Hz}$ to $10^{2.8} \mathrm{~Hz}$ at $20{ }^{\circ} \mathrm{C}$

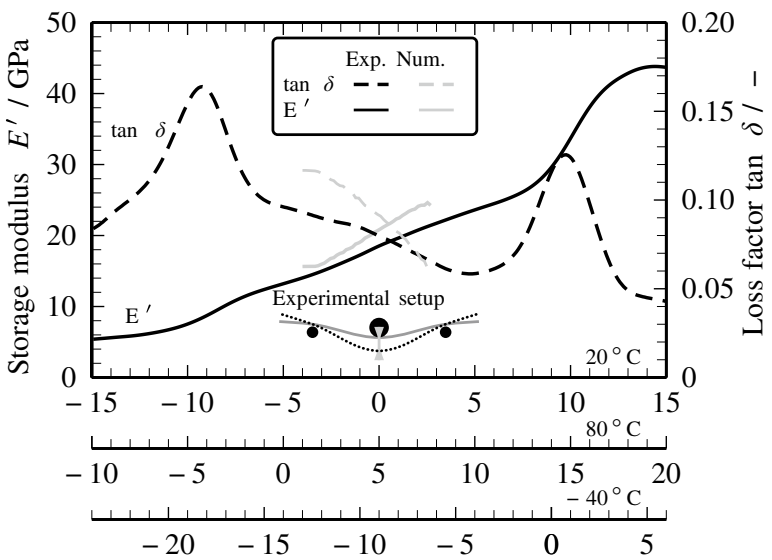

Frequency $\log _{10}\left(f_{r}\right) / \mathrm{Hz}$ 
predicted loss factor $\tan \delta$ for low frequencies is $25 \%$ higher, for high frequencies it is $8 \%$ smaller than the results from the experimental master curve.

\subsection{Modal Analysis with Cantilever Beam Experiment and Sweep Excitation}

A representative FRF (here dynamic compliance [36]: input is the driving force, output the displacement) of a specimen in the cantilever beam experiment can be seen in Fig. 8 for one of three tested specimens.

Due to the high damping, only five natural frequencies can be detected, with the highest at about $1700 \mathrm{~Hz}$. The number of modes that can be detected is related to the frequency range of the excitation and the sensitivity and placement of the measuring capacitive sensor. Although the excitation was performed up to $6000 \mathrm{~Hz}$, higher modes could not be detected due to the lower displacement amplitude at higher frequencies and the limited sensitivity of the capacitive sensor. It can be assumed that only bending modes are detected due to the placement of the capacitive sensor and the attached magnet in the middle of the $15 \mathrm{~mm}$ wide specimens. The mean values of the first five natural frequencies with the corresponding loss factors from the experimental investigations and the numerical and the RKU model are listed in Table 4. For both models the relative deviation to the mean experimental values is given in parentheses.

It can be seen that the increase of the natural frequency and mode shape leads to increasing loss factors $\eta$ due to the CLD behavior of the HyCEML. However, the numerical model and the RKU model both overestimate the natural frequencies between $27 \%$ to $66 \%$ and $14 \%$ to $16 \%$ respectively. Except for the first bending mode, which can show increased damping due to the clamping according to ASTM E75605 [12], the loss factors for the RKU model and the experiment match well within a deviation between - 5\% to $34 \%$. The numerical model shows a larger deviation for these modes. Besides the neglection of the additional mass (magnet) in both models, the one-sided clamping can also cause a shift in the experimental natural frequencies. The clamping is assumed to be ideal in both models, but especially at high frequencies the experimentally determined values can be prone to errors due to softening of the clamping and influencing of the natural frequencies [40]. The differences in the numerically and analytically determined natural frequencies are believed to result from the different modeling approaches. While the RKU model uses homogenized layers, leading to an equal modulus under

Fig. 8 FRF for one of three cantilever experiments for a specimen with $210 \mathrm{~mm}$ free length

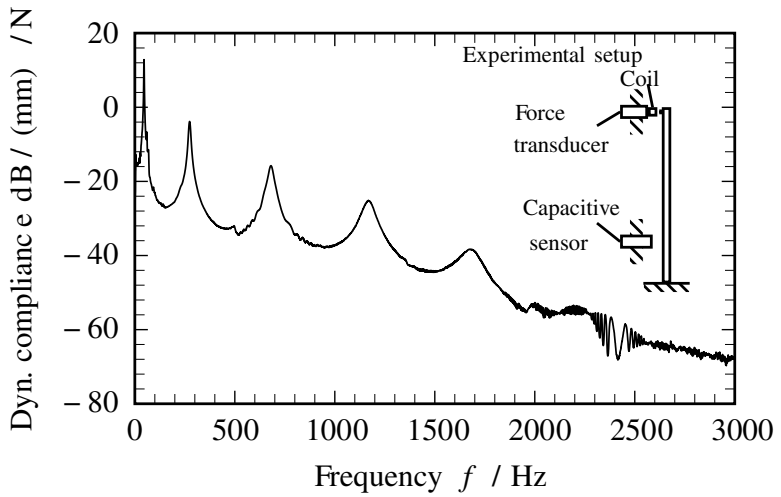


Table 4 Mean value and standard deviation of natural frequencies and loss factors $\eta$ of the three tested coupon specimen with $210 \mathrm{~mm}$ free length and $15 \mathrm{~mm}$ width from the cantilever beam experiment. For both models the relative deviation to the experimental values is given in parentheses

\begin{tabular}{|c|c|c|c|c|c|c|}
\hline \multirow{2}{*}{\begin{tabular}{l|l}
$+z$ & Mode \\
$-z$ & Shape*
\end{tabular}} & \multicolumn{3}{|c|}{ Natural freq. / Hz } & \multicolumn{2}{|c|}{ Loss factor / 10} & \multirow{2}{*}{$\begin{array}{l}-3 \\
\eta_{\mathrm{RKU}}\end{array}$} \\
\hline & $f_{\text {exp }}$ & $f_{\text {num }}$ & $f_{\mathrm{RKU}}$ & $\eta_{\exp }$ & $\eta_{\text {num }}$ & \\
\hline & $47.9 \pm 0.9$ & $79.4(+66 \%)$ & $55.6(+16 \%)$ & $21 \pm 3$ & $12(-43 \%)$ & $5(-76 \%)$ \\
\hline$=$ & $275.2 \pm 6.5$ & $401.9(+46 \%)$ & $320.2(+16 \%)$ & $28 \pm 3$ & $49(+75 \%)$ & $24(+17 \%)$ \\
\hline$=0$ & $676.5 \pm 22$ & $918.6(+36 \%)$ & $777.1(+15 \%)$ & $35 \pm 7$ & $68(+94 \%)$ & $47(+34 \%)$ \\
\hline$-1=0$ & $1146 \pm 60$ & $1482(+29 \%)$ & $1305(+14 \%)$ & $61 \pm 2$ & $81(+33 \%)$ & $64(+5 \%)$ \\
\hline 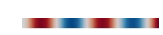 & $1633 \pm 85$ & $2077(+27 \%)$ & $1875(+15 \%)$ & $76 \pm 4$ & $88(+16 \%)$ & $72(-5 \%)$ \\
\hline
\end{tabular}

*Thumbnails obtained from numerical study.

tension and bending, the numerical model shows a higher flexural modulus due to the fiber orientation in the $[0 / 90]_{\mathrm{S}}$ lay-up of the CFRP layers. Possible adverse effects, which lead to an overestimation of the natural frequencies for the numerical model compared to the experimental results, are discussed in Sec. 5.2.2.

\subsection{Modal Analysis with Free Boundaries and Pulse Excitation}

The FRF (here mobility: input is the driving force, output the velocity) of coupon specimens under free-free boundary conditions can be seen in Fig. 9. The natural frequencies and corresponding loss factors from the experimental, the analytical and the numerical study are summarized in Table 5 .

Not all mode shapes that are determined numerically can be measured experimentally (second torsional mode shape for the $30 \mathrm{~mm}$ wide specimen). It can be seen that with increasing frequency the damping of the considered mode shape also increases due to the CLD mechanism. The discrepancy between experimentally and numerically determined natural frequencies decreases with increasing frequency from $16.2 \%$ to $12.4 \%$. For the RKU model the deviation is between $0.2 \%$ and $3.9 \%$. The loss factors are modeled with a deviation of $1.2 \%$ to $36 \%$ for the numerical and $6.6 \%$ to $37 \%$ for the RKU model.

For the panel the experimentally determined FRF can be seen in Fig. 10. The resulting natural frequencies and mode shapes from the experimental and numerical modal analysis are summarized in Table 6.

Fig. 9 Average specific spectral mobility of a coupon specimen $(125 \mathrm{~mm} \times 30 \mathrm{~mm})$

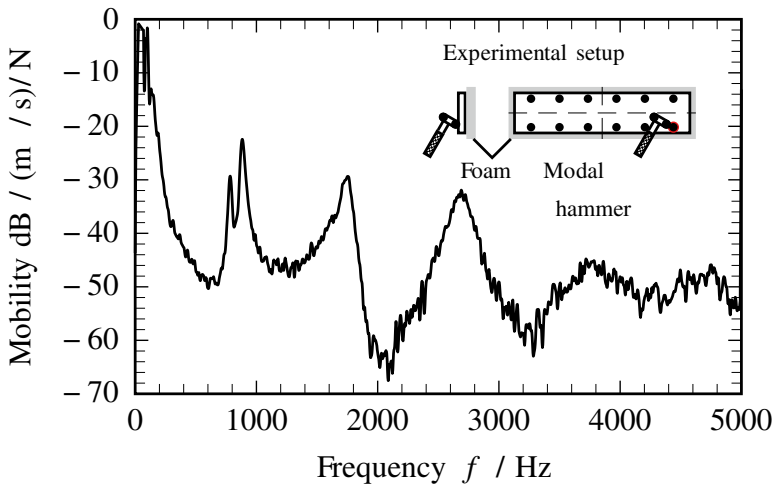


Table 5 Experimental, analytical and numerical results of mode shapes, natural frequencies and loss factors $\eta$ of a coupon specimen $(125 \mathrm{~mm} \times 15 \mathrm{~mm})$ and $(125 \mathrm{~mm} \times 30 \mathrm{~mm})$ from modal analysis with pulse excitation

\begin{tabular}{|c|c|c|c|c|c|c|c|}
\hline \multirow{2}{*}{$\begin{array}{l}\Xi \\
\Xi \\
\vdots \\
\times \\
-\end{array}$} & & \multicolumn{3}{|c|}{ Natural freq. / Hz } & \multicolumn{2}{|c|}{ Loss factor $/ 10$} & \multirow{2}{*}{$\begin{array}{l}-3 \\
\eta_{\mathrm{RKU}}\end{array}$} \\
\hline & ${ }_{-z}$ shape* & $f_{\text {exp }}^{+}$ & $f_{\text {num }}$ & $f_{\mathrm{RKU}}$ & $\eta_{\exp }^{+}$ & $\eta_{\text {num }}$ & \\
\hline \multirow{5}{*}{ 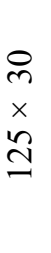 } & & $786 / 771$ & 929 & 787 & $40 / 36$ & 38 & 47 \\
\hline & ב & $889 / 901$ & 816 & - & $47 / 46$ & 46 & - \\
\hline & & $1762 / 1772$ & 1929 & 1705 & $48 / 57$ & 71 & 72 \\
\hline & 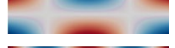 & - & 1699 & - & - & 57 & - \\
\hline & & $2685 / 2693$ & 3015 & 2679 & $69 / 73$ & 80 & 83 \\
\hline \multirow{4}{*}{$\begin{array}{l}n \\
\times \\
\stackrel{n}{n} \\
\simeq\end{array}$} & & & & & & & \\
\hline & e & $812 / 830$ & 929 & 787 & $37 / 50$ & 38 & 47 \\
\hline & en a d a & $1683 / 1706$ & 1928 & 1705 & $63 / 71$ & 71 & 72 \\
\hline & enanan & $2669 / 2678$ & 3015 & 2679 & $82 / 95$ & 81 & 83 \\
\hline
\end{tabular}

* Thumbnails obtained from numerical study. ${ }^{+}$Values for both specimens per width.

In the FRF, natural frequencies can only be distinguished up to about $1 \mathrm{kHz}$. Above that, the modes are highly damped so that no more individual natural frequencies can be determined. Again, not all mode shapes that have been identified numerically could also be distinguished experimentally, but for a better representation of the loss factor trend, all numerical mode shapes are shown. Except for the first mode shape, a clear increase of loss factor with higher mode shapes can be seen for the numerical results and rotated mode shapes appear closely spaced on the frequency scale. For the experimental results the loss factors show a higher fluctuation, especially for the first few mode shapes. While the experimentally determined loss factor for the second mode shape matches the numerically determined value well, the first, third, fifth and sixth frequency shows much higher fluctuations. For the seventh and eleventh frequency the experimental and numerical results are again in better agreement with a deviation of $20 \%$ and $28 \%$. However, for the second, seventh and

Fig. 10 Average specific spectral mobility of the panel $(380 \mathrm{~mm} \times 380 \mathrm{~mm})$

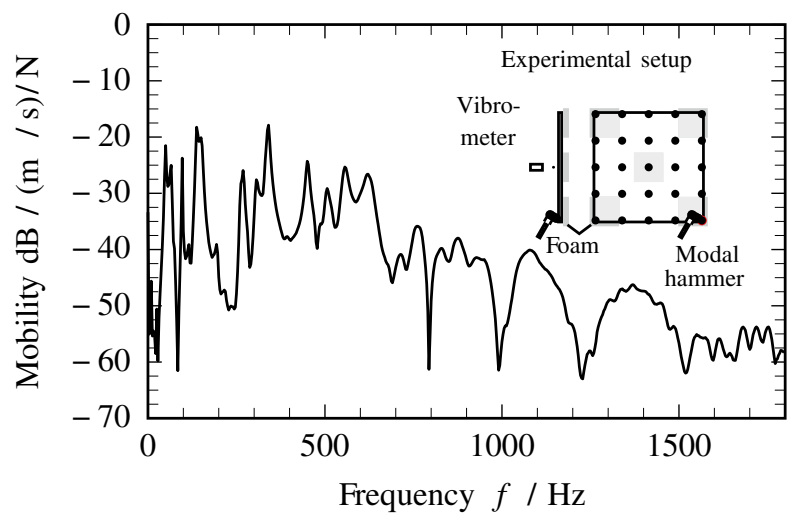


Table 6 Experimental and numerical results of mode shapes, natural frequencies and loss factors $\eta$ of the panel $(380 \mathrm{~mm} \times 380 \mathrm{~mm})$ from modal analysis with pulse excitation. For the numerical model the deviation to the experimental results is given in parentheses. For all mode shapes the outer fibers of the specimens are oriented along the $\mathrm{x}$-direction

\begin{tabular}{|c|c|c|c|c|c|}
\hline \multirow[b]{2}{*}{ No. } & \multirow{2}{*}{$\begin{array}{l}z \\
z \text { shape* }\end{array}$} & \multicolumn{2}{|c|}{ Natural freq. $/ \mathrm{Hz}$} & \multicolumn{2}{|c|}{ Loss factor $/ 10^{-3}$} \\
\hline & & $f_{\exp }$ & $f_{\text {num }}$ & $\eta_{\exp }$ & $\eta_{\text {num }}$ \\
\hline 1. & $\underset{x}{x}$ & 55 & $27(-51 \%)$ & 72.9 & $16.8(-77 \%)$ \\
\hline 2. & - & 98 & $114(+16 \%)$ & 4.5 & $7.7(+71 \%)$ \\
\hline 3. & 2 & 136 & $117(-16 \%)$ & 36.0 & $8.4(-77 \%)$ \\
\hline 4. & $\overline{1}$ & - & 127 & - & 11.3 \\
\hline 5. & $1=$ & 151 & $128(-18 \%)$ & 51.2 & $10.9(-78 \%)$ \\
\hline 6. & $=2$ & 193 & $195(+1 \%)$ & 26.4 & $15.7(-41 \%)$ \\
\hline 7. & 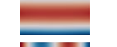 & 279 & $297(+6 \%)$ & 19.8 & $23.9(+20 \%)$ \\
\hline 8. & & - & 303 & - & 22.9 \\
\hline 9. & $5-1$ & - & 305 & - & 24.2 \\
\hline 10. & $1=3$ & - & 314 & - & 24.3 \\
\hline 11. & $t=1$ & 337 & $352(+4 \%)$ & 20.5 & $26.3(+28 \%)$ \\
\hline 12. & $\left\{\begin{array}{l}101 \\
10=1\end{array}\right.$ & - & 356 & - & 25.6 \\
\hline 13. & $10 \pm 1$ & - & 473 & - & 30.9 \\
\hline
\end{tabular}

eleventh mode the numerical results still show a $4 \%$ to $16 \%$ higher frequency. The $20 \%$ to $71 \%$ higher loss factor for these frequencies can be related to an overestimated constraining layer stiffness by the model (see Sec. 5.2).

\subsection{Wave Attenuation Analysis}

The wave attenuation analysis is only conducted experimentally, as the numerical model is only applicable in the frequency domain. The results of the fixed frequency excitation are presented as the out-of-plane velocities of the high density measurement field on the panel at constant time steps of $0.012 \mathrm{~ms}$. Figure 11 shows time steps from $0 \mathrm{~ms}$ to $180 \mathrm{~ms}$ with the excitation point in the middle of each figure. 
Concentric wave patterns can be distinguished which propagate in elliptical form from the excitation. The coordinate system in the first picture represents the fiber orientation of the outermost unidirectional CFRP layer. Figure 12 shows the out-of-plane velocities in $0^{\circ}, 45^{\circ}$ and $90^{\circ}$ direction for the excitation frequency of $5 \mathrm{kHz}$. The attenuation with decreasing distance from the excitation point can be clearly seen. Different wavelengths in $0^{\circ}, 45^{\circ}, 90^{\circ}$ direction result from the orthotropic CFRP face layers. In $0^{\circ}$ direction the longest semi wavelength with $21 \mathrm{~mm}$ occurs. The semi wavelengths in $45^{\circ}$ and $90^{\circ}$ direction are about $17.5 \mathrm{~mm}$. The attenuation rate, which can be seen as the envelopes of the travelling maxima of the waves in Fig. 12 shows the highest attenuation for the $45^{\circ}$ direction while the $0^{\circ}$ and $90^{\circ}$ direction decay about the same.
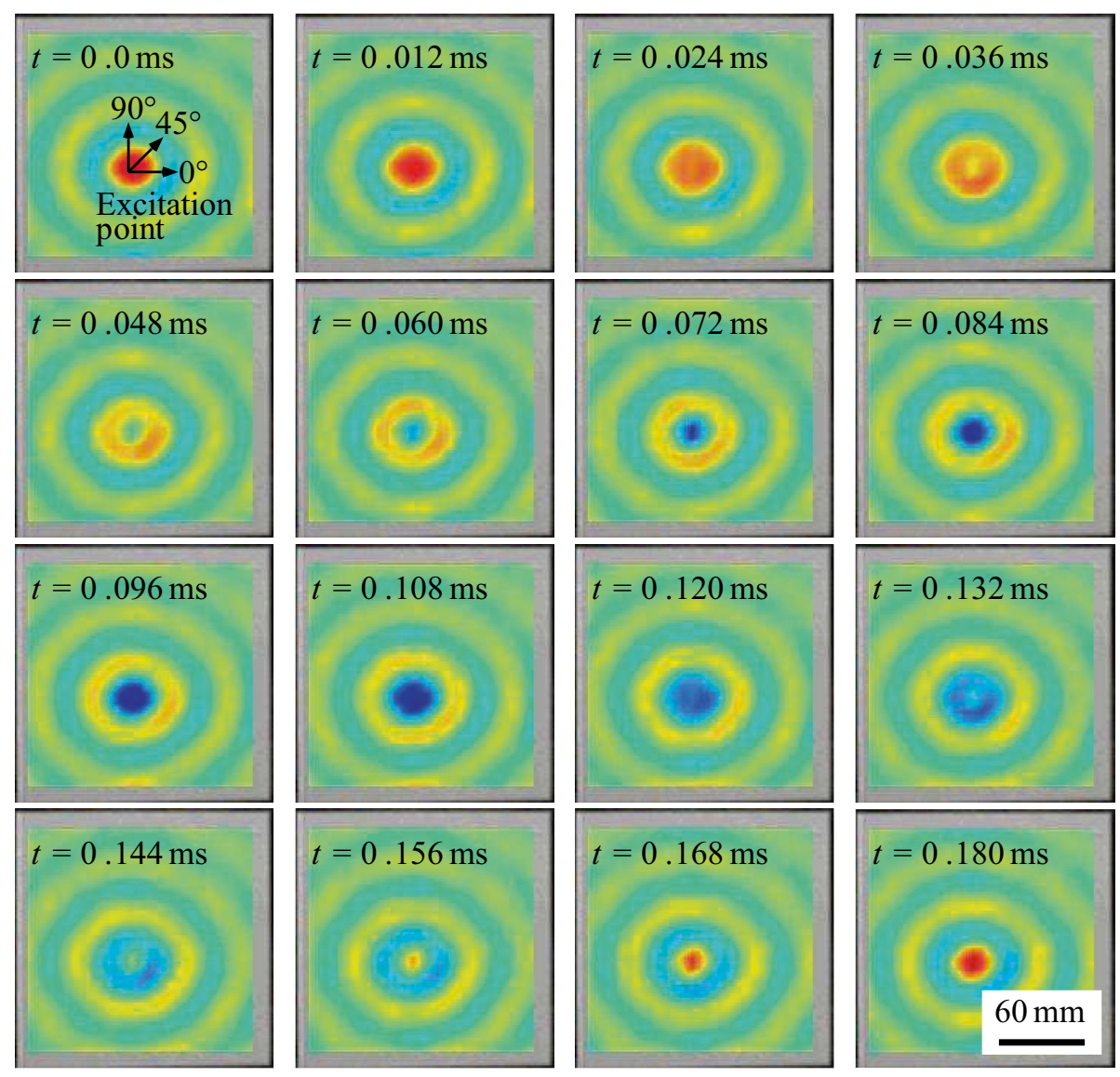

Fig. 11 Experimental result of a running wave sequence $(\Delta t=0.012 \mathrm{~ms})$ from the panel $(380 \mathrm{~mm} \times 380 \mathrm{~mm})$ at a fixed excitation frequency of $5 \mathrm{kHz}$. Visualized is the out-of-plane velocity of the evaluated section of the reflective foil, as described in Fig. 6 (grey area). The outer fibers of the panel are oriented along the $0^{\circ}$ direction 
Fig. 12 Out-of-plane velocity in $0^{\circ}, 45^{\circ}$ and $90^{\circ}$ direction for the excitation at a fixed frequency of $5 \mathrm{kHz}$. The outer fibers of the panel are oriented along the $0^{\circ}$ direction. Solid lines: representative curve. Dashed lines: Envelope of the traveling waves

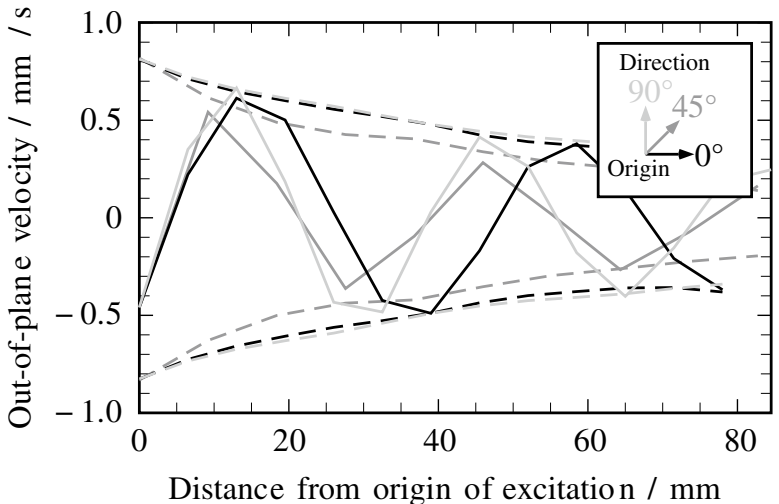

\section{Discussion}

\subsection{Manufacturing Influences}

In general, the panel from which the coupon specimens are cut out is manufactured in a hot molding process. During the manufacturing process the recommendations of the manufacturers are followed, therefore it is assumed, that defects like voids are prevented and that polymers are fully cured or vulcanized, respectively. Although the neat materials and the HyCEML are consolidated with the same manufacturing parameters, it cannot be completely excluded that the characterization of the individual materials and subsequent superposition may not reflect the behavior of the hybrid in its entirety. Owing to the stacking of the laminate by hand and local disparities in the composition of HyCEML constituents, e.g. the thickness of the elastomer or the CFRP etc. (see Fig. 1), there are further structural characteristics which could affect the vibration and damping behavior of HyCEML. In particular, the fiber orientation of the unidirectional CFRP plies can vary due to resin flow out of the shearing gap, which acts as a seal in the mold during the manufacturing process. However, this is not further analyzed within this study.

\subsection{Interpretation and Comparability of Different Test Setups}

In this study, different experimental setups are tested on the same HyCEML layup to cover a broad frequency range and cover different damping phenomena. Each method has its characteristics and properties, which can lead to deviations between the models and the experimental results and will be discussed in the following. Although the focus of this paper lies on the comparison of the results from different test methods, a comparison to the modeling of each setup will also be discussed, with the aim of ascribing substantial differences between the experiments and the models to aspects of the experimental procedures or material effects that have not been taken into account. For example nonlinear viscoelasticity is neglected which can show an effect on the damping behavior of CLD [41]. Also three dimensional stress states in the elastomer layers, which might occur especially at higher frequencies, are neglected [42]. Different excitation methods on various specimen geometries are presented and different damping values are calculated. However, as stated before for small loss factors $\eta \ll 1$ the statement $\eta=2 \vartheta=\tan \delta$ should hold true. In order to 
compare the individual measured values with each other, Fig. 13 summarizes the damping values determined in the 3PB DMA (Fig. 13a), the cantilever beam setup (Fig. 13b), the modal analysis under free-free boundary conditions on the coupon specimen (Fig. 13c) and on the panel (Fig. 13d).

\subsubsection{Three Point Bending Dynamic Mechanical Analysis}

The DMA experiments (tension, torsion and 3PB) are performed in a non-resonant mode below the first natural frequency of the specimens, thus the specimens are always deformed in the same way. This can be used to analyze the viscoelastic material behavior independent of the mode-specific damping behavior. The master curves of the neat elastomer (see Fig. 3b) and of the HyCEML (see Fig. 13a) show the same trend at room temperature. For increasing frequencies up to $10^{4} \mathrm{~Hz}$ at $T_{\text {ref }}=20{ }^{\circ} \mathrm{C}$ the storage modulus increases, and the loss factor $\tan \delta$ decreases. Thus, it is assumed that the behavior of the loss factor $\tan \delta$ in the 3PB experiment is mostly influenced by the elastomer for this temperature and frequency range. Previous studies on neat CFRP under tension have also shown only little influence

a)

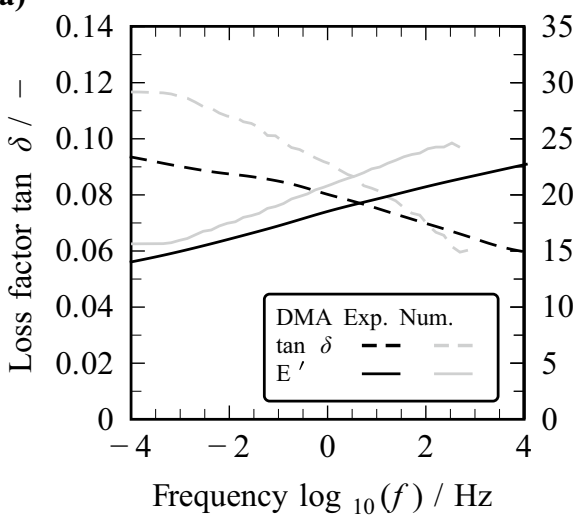

c)

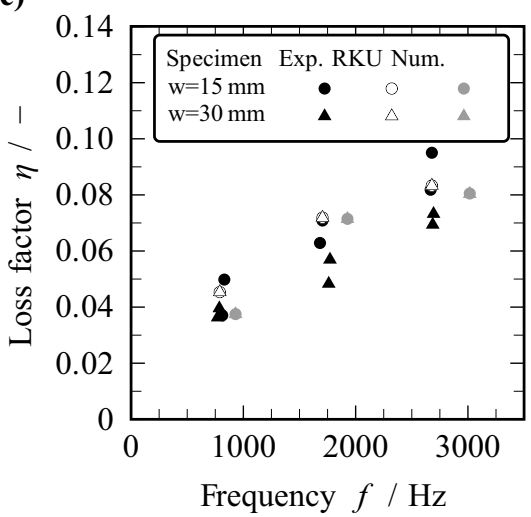

b)

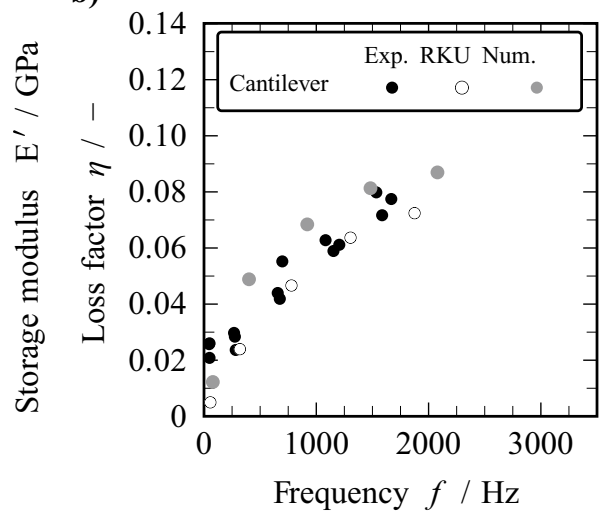

d)

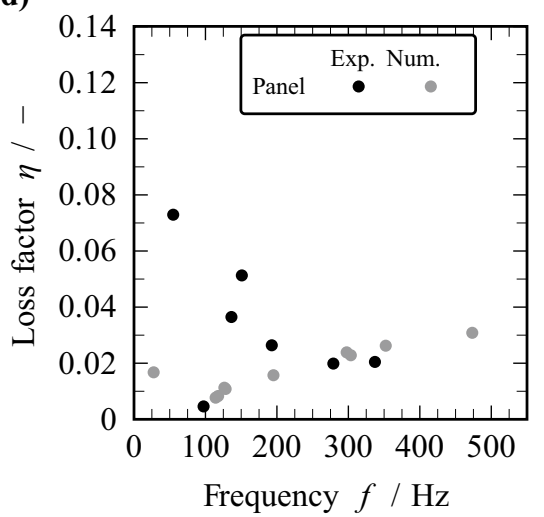

Fig. 13 Loss factors $\tan \delta$ and $\eta$ of coupon specimens and panel with regard to their test setup for a) DMA master curve, b) cantilever beam experiment, c) modal analysis with pulse excitation for coupon specimens (only bending modes are displayed) and d) modal analysis with pulse excitation for the panel 
on the loss factor of the CFRP for this temperature and frequency range [27]. The comparison of numerical and experimental results in Fig. 13a shows that the numerical model predicts a higher storage modulus, which also explains the higher natural frequencies in the modal analysis on the coupon specimen and cantilever beam in Fig. 13b and c. The decrease of loss factor in both, experimental and numerical study can be related to the elastomer as the same trend can be found in the master curve of the neat elastomer. The more severe decline of the loss factor $\tan \delta$ in the numerical model suggests a slightly different material behavior of the neat elastomer and the elastomer in the HyCEML. This can be due to manufacturing differences or due to different strain amplitudes in the DMA characterization on the neat elastomer and the elastomer in the hybrid material. This would suggest the presence of viscoelastic non-linearities. The projected behavior of the master curve at very low frequencies or high temperatures should be experimentally confirmed, since thermorheological complex material behavior might exist when two different relaxation mechanisms overlap. Therefore, additional vertical shifts for the master curves generated may be necessary. However, it is also assumed that the behavior over a small frequency range from $10^{-4} \mathrm{~Hz}$ to $10^{4} \mathrm{~Hz}$ can be predicted correctly [43]. It should also be mentioned that the viscoelastic interlayer can significantly reduce the bending stiffness of the laminate, but increase the damping and therefore a trade-off between damping and stiffness must be considered. The influence of different laminate lay-ups on the stiffness and damping behavior in $3 \mathrm{~PB}$ configuration was shown in [33].

\subsubsection{Modal Analysis with Cantilever Beam Experiment and Sweep Excitation}

In contrast to the DMA master curves the loss factor determined from cantilever beam experiment increases with increasing frequencies. This behavior can be explained by the higher shear strains at higher bending modes of the cantilever beam setup. This is a well known phenomenon for CLD applications and is also depicted by the numerical and analytical RKU approach. Except for the first bending mode, the analytical model can predict the overall behavior well (see Table 4 and Fig. 13b). According to ASTM E756-05 [12] the deviation in the first bending mode shape can be attributed to the clamping of the specimen, which might also influence the higher frequencies due to a softening of the clamping. This can lead to lower natural frequencies compared to both modeling approaches.

Although the $\tan \delta$ of the pure elastomer and of the HyCEML under bending decreases with increasing frequency, the influence of the wavelength is significant enough so that the modal loss factor of the HyCEML increases for higher modes and higher frequencies. The change in material behavior due to the frequency-dependent viscoelastic properties at room temperature is significantly lower than the influence of the mode shape. This is an important result, which can be drawn by the comparison of the same frequency range in Fig. 13a and $\mathrm{b}$, and highlights the importance of considering the mode shape. A direct comparison of the loss factors from the 3PB DMA can be made when the semi wavelength of both experiments is the same. For the cantilever beam the fourth bending mode shape results in a semi wavelength of $60 \mathrm{~mm}$ (determined with Eq. (7)). The 3PB deformation results in approximately the same length, as due to the stiff constraining layers a smaller semi wavelength than the support distance of $80 \mathrm{~mm}$ is observed [44]. The experimentally determined loss factor for the fourth bending mode shape of the cantilever beam experiment (0.061 see Table 4) shows good accordance with the DMA master curve for the HyCEML at the same frequency (see Fig. 13a: 0.063 at a frequency of $1146 \mathrm{~Hz}$ ). The RKU-model leads to a loss factor of 0.064 for the fourth natural frequency (see Table 4) showing good 
accordance with the DMA experiment as well. Hence, comparable loss factors can be determined by these two methods. However, the pure frequency dependence of the viscoelastic material behavior is superimposed by the wavelength dependence, which leads to the different damping behavior in the modal analysis.

The numerically determined natural frequencies and loss factors are generally higher than those from the analytical model. This might result from the different modeling approaches of the CFRP layers. The numerical simulation takes into account the $[0 / 90]_{\mathrm{S}}$ lay-up of the CFRP face sheets, which results in a higher flexural modulus of the face sheets. The analytical approach uses a homogenized modulus, determined with a volumetric rule of mixture $\left(E^{0 / 90}=\left(E^{0}+E^{90}\right) * 0.5\right)$. Computing the numerical model with homogenized CFRP layers and the exact same material parameters as in the analytical approach, also showed significantly lower deviations of the natural frequencies and loss factors between the two models, as it is shown in Fig. 14. The overestimation of the natural frequencies from the numerical model compared to the experimental results also leads to the conclusion that the material data of the $0^{\circ}$ CFRP, presented in Table 1 , overestimates the stiffness of the unidirectional CFRP layer. Thus, the use of a volumetric rule of mixture leads to smaller deviations from the experimental findings in this case. The overestimation of the $0^{\circ} \mathrm{CFRP}$ stiffness could be attributed to different strain ranges in the quasistatic characterization of the CFRP according to EN ISO 527 [22] and in the modal analysis. Due to a higher strain range in the quasistatic characterization compared to the modal analysis and an increasing modulus of the CFRP in fiber direction for higher strains, the modulus is overestimated by the tensile tests. Furthermore, an anisotropic behavior in tension or compression, which might exist for the CFRP, is not characterized and modeled [45]. In addition, the master curve of the rheometer, which shows a slightly stiffer behavior compared to the characterization under tension (see Fig. 7a), was used in both models for the elastomer. Furthermore, the softening of the clamping is not reflected by the modeling approaches. This might also explain the higher natural frequencies of both models, compared to the experimental results. An increasing offset between the RKU approach and a numerical

Fig. 14 Modal loss factor and natural frequencies of a $210 \mathrm{~mm}$ long HyCEML cantilever beam. Comparison of the two modeling approaches when assuming homogenized, isotropic, linear elastic behavior for the CFRP layers in both models. Material data for both models as described in Sec. 3.3

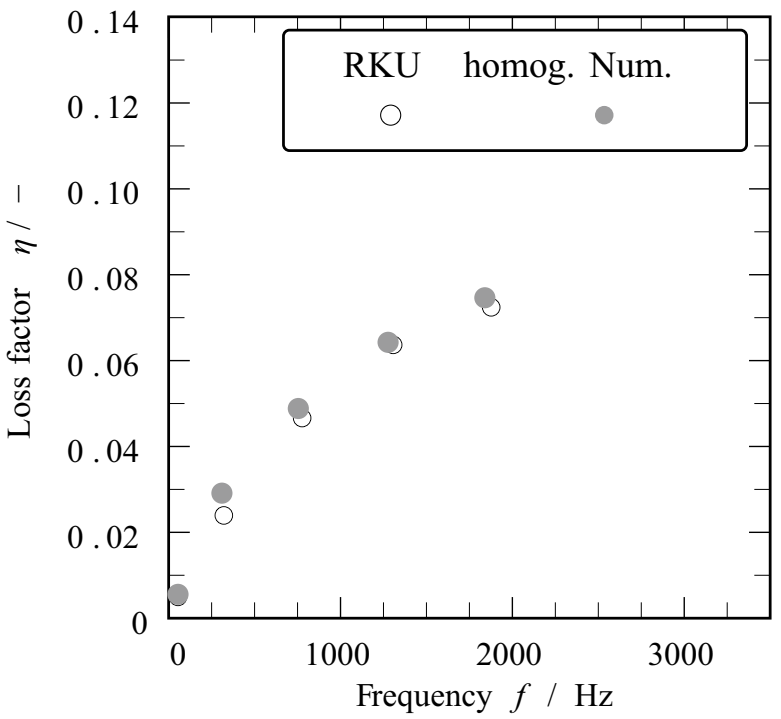


simulation was also shown in a study by Cortés et al. [46] for a symmetrical three layer configuration, limiting the analytical approach for thick damping layers. This can explain the remaining differences between both models shown in Fig. 14. Nevertheless, the models both show the same damping behavior with increasing loss factors of the HyCEML, which results from the increased shearing of the damping layers at lower wavelengths.

\subsubsection{Modal Analysis with Pulse Excitation}

The same tendency as described for the cantilever beam setup can be found for the modal analysis on the coupon specimens in Fig. 13c. With increasing frequency the modal loss factor $\eta$ increases. The torsional mode shapes are not considered in this figure, because the analytical approach is not applicable for torsional mode shapes and because the shear states of bending and torsion are not comparable [13]. However, they also show the same trend, that higher torsional mode shapes lead to higher modal loss factors. The increasing loss factors can be explained by the shorter wavelength, leading to higher shear strains in the elastomer layers. The difference of experimentally determined loss factors between the $15 \mathrm{~mm}$ and $30 \mathrm{~mm}$ wide specimens cannot be seen in the numerical model and the RKU model. This indicates that this deviation is within the experimental scatter range of the damping values. The semi wavelength of the mode shapes can also be determined using (Eqs. 6 and 7). Thus, the first bending mode shape vibrates with a semi wavelength of $83.3 \mathrm{~mm}$, which is in the same range as the third bending mode shape of the cantilever setup $(84 \mathrm{~mm})$. As a result, the loss factors of these two configurations are in the same range and can be compared.

When comparing the test setup to the cantilever setup, the specimen length of $210 \mathrm{~mm}$ for the cantilever setup leads to more bending mode shapes in the evaluable frequency range compared to the specimen length of $125 \mathrm{~mm}$ in the modal analysis with pulse excitation. Hence, the analytical and numerical model can be validated on more points. However, for the $30 \mathrm{~mm}$ wide specimen, with an excentric excitation, additional torsional mode shapes can be detected, which can be used for further damping measurements. This requires a multi-point measurement of the specimen, to clearly separate the modes. In comparison, the simple one point measurement in the cantilever setup makes it possible to integrate the measurement setup in a temperature chamber and carry out temperature-dependent measurements. However, this is beyond the scope of this paper.

The experimentally and numerically determined damping values of the panel (Fig. 13d) show greater deviation in the lower frequency range up to $200 \mathrm{~Hz}$. This can be explained by the supporting foam of the panel during the experiment at the edges and the middle according to Fig. 5b. For mode shapes with wave minima or maxima at the supports (Table 6: Mode shape 1, 3, 5 and 6), the loss factor in the experiment are significantly higher than in the numerical model. For mode shape 2, however, the loss factor values in experiment and the simulation match with a deviation of $71 \%$. For the seventh and eleventh mode shape the deviation between experiment and simulation also decreases below $30 \%$ as the amplitude of vibration decreases for higher natural frequencies, and the support elements cover a decreasing fraction of vibration antinodes transmitting the energy into the supporting foam material. The higher loss factors compared to the experimental results represents the same trend as in the cantilever experiments, where the numerical model predicts higher natural frequencies and higher loss factors, which is believed to result from overestimated CFRP stiffness. The high damping and low amplitude at higher frequencies leads to the 
elimination of any natural frequencies above approximately $1000 \mathrm{~Hz}$ for the presented test setup. In the numerical study, however, a steady increase of loss factor with higher frequency for the determined mode shapes (except for the first natural frequency) can be seen. The higher damping of the first mode shape may result from the orthotropic CFRP lay-up and the associated lower torsional stiffness.

In general, the larger panel leads to more modes in the same frequency compared to the smaller specimens. However, this also leads to a stronger overlap of neighboring modes, which can require MDOF approaches. In addition, the supporting on foam showed a strong influence on some modes for the panel and might influence the results for the specimens. According to Ewins [47], the frequency of the highest rigid body mode of the test setup should be lower than $10 \%$ to $20 \%$ of the first bending mode, to reduce the influence of the supports. This might be the case for the specimen geometry with the first bending mode at around $900 \mathrm{~Hz}$. For the panel, however, the lower natural frequencies might also be influenced by rigid body modes. According to Crane et al. [48] this mainly influences the damping of the investigated structure, rather than the natural frequencies. In general, modal analyses on lightweight materials, especially with small specimen size, are difficult to perform [49]. In a study, which compares the specimen support on foam with support on a specially designed air bed, the effect on additional damping was less pronounced for the foam bedding, proving the applicability for small specimens [50]. For future investigations on panels, however, different support conditions (free hanging panels for example) could be considered to further improve the damping measurements on larger HyCEML geometries. A rectangular panel geometry could also help to increase the difference in natural frequency between rotated mode shapes. In addition, a higher frequency resolution of the FFT might help to increase the accuracy in the lower frequency range.

It should be noted that although the experimental results from the modal analysis on the specimens and the cantilever as well as the numerical results of the panel show an increasing loss factor for higher mode shapes / shorter wavelengths, the numerical and the RKU model predict a maximum loss factor for a certain mode shape / wavelength. However, this frequency is beyond the displayed scale in Fig. 13b, c and d. Above this frequency or below this wavelength the loss factors for higher bending mode shapes decrease. This behavior results from the wavelength dependency of the CLD mechanism superimposed to the frequency dependency of the viscoelastic material behavior. However, these modes are not determined experimentally as the high overall damping results in only few natural frequencies. This is due to the limited power input at high frequencies with the modal hammer excitation and the limited sensitivity of the capacitive sensor for the small amplitudes at higher frequencies in the cantilever setup.

Although differences exist between the models and the experimental results, especially the numerical approach can be used to model more complex HyCEML structures in order to evaluate and optimize their dynamic behavior. The model can also be used for different material combinations if the corresponding material data sets are available. Furthermore, more complex laminate lay-ups can be modeled numerically, which, however, is not part of this study. Yet, it was shown that proper material data is needed to reflect all aspects. This is shown by comparing and discussing the results of different test setups. Especially nonlinear material behavior of the CFRP and the elastomer can lead to a deviation between experiment and model and will be further investigated in future studies. Therefore, a characterization of the constituents in comparable strain amplitudes as in the modal analysis might improve the models. 


\subsubsection{Wave Attenuation Analysis}

Due to the high damping of the HyCEML, natural frequencies of a given structure can only be measured up to a certain frequency limit by using a usual modal analysis setup. The suppression of mode shapes can be explained by the fact, that sufficiently short, locally excited waves are strongly attenuated before they reach the edge of the vibrating structure. An analysis of such spatially attenuated waves instead of mode shapes in the higher frequency range can provide important insights into the vibration behavior of a highly damped structure itself and help to characterize the energy conducting paths into neighboring components.

For the cantilever beam setup the highest measurable natural frequency is at approximately $1600 \mathrm{~Hz}$ (see Table 4), while for the modal analysis the specimen's natural frequencies up to $2693 \mathrm{~Hz}$ (see Table 5) can be detected. For the panel only frequencies up to around $1000 \mathrm{~Hz}$ can be detected for the excitation with the modal hammer (see Fig. 10). Non-stationary mode shapes can be considered as running waves with no stationary node lines from the FRF [51]. Therefore, a forced excitation at fixed frequencies above the cutoff range was conducted as described in Sec. 3.2.4. The high damping of the HyCEML leads to a distinct formation of running, nonreflected waves already in a frequency range of $5 \mathrm{kHz}$. The damping is sufficiently high that a single excitation force becomes a source of spatially attenuated waves already at middle-range acoustical frequencies for the here considered panel size and excitation. Comparable wave patterns and a dissipation behavior depending on the fiber orientation are also determined numerically by Manconi et al. [52] for a composite sheet with viscoelastic core. The attenuation of the running waves in the study at hand depends on the fiber orientation due to the orthotropic CFRP lay-up (see Fig. 12). While the Young's modulus of the CFRP layer in $0^{\circ}$ and $90^{\circ}$ is about $55 \mathrm{GPa}$, it is only $15.1 \mathrm{GPa}$ in $45^{\circ}$ direction. Therefore, the CLD mechanism leads to different attenuation due to different face sheet stiffnesses. The shorter wavelength in $90^{\circ}$ direction compared to the $0^{\circ}$ direction can be explained by the lower bending modulus of the orthotropic $[0 / 90]_{\mathrm{S}}$ lay-up.

To describe the wave attenuation and damping in $0^{\circ}, 90^{\circ}$ and $45^{\circ}$ direction a $380 \mathrm{~mm}$ long (same length as the panel size), free-free beam is investigated using the RKU model presented in Sec. 3.3. Figure 15 shows the loss factors over the semi wavelength for this configuration.

For the second longest semi wavelength in $0^{\circ}$ and $90^{\circ}$ direction the loss factor of $\eta=0.210$ is also in the same range as for the corresponding mode shape determined by the experimental and numerical modal analysis on the panel shown in Table 6 (mode nr.

Fig. 15 Loss factor over semi wavelength for a $380 \mathrm{~mm}$ long HyCEML beam with free-free boundary conditions in $0^{\circ}, 45^{\circ}$ and $90^{\circ}$ direction modeled with the RKU model

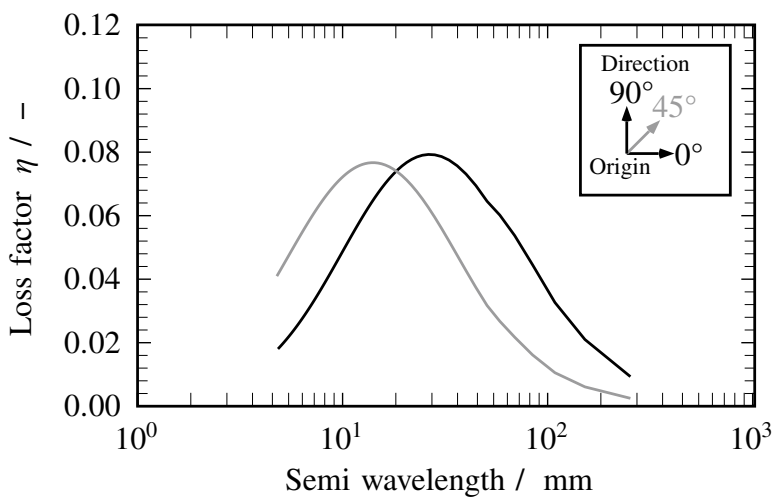


7 and 8). It can also be seen that for long wavelengths / low frequencies the damping in $0^{\circ}$ and $90^{\circ}$ direction is higher, than for the $45^{\circ}$ direction. This was also expected by Liao et al. [53] when the damping of the face sheets is neglected. The increase of the loss factor considering the damping of the face sheets is considered to be small for the present material combination. In comparison to the study by Liao et al. [53], which proposes to take CFRP damping into account, the elastomer layer used in our study is about 13 times thicker and only half as stiff. It can therefore be expected, that the elastomer and the CLD mechanism resulting from the hybrid laminate, are mainly responsible for damping. Nevertheless, although the damping of the CFRP layer is neglected in the RKU model, Fig. 15 shows that below a semi wavelength of about $20 \mathrm{~mm}$ the loss factor of the $\pm 45^{\circ}$ fiber orientation is higher than the $0^{\circ}$ and $90^{\circ}$ orientation. This explains the higher attenuation of the running waves in $45^{\circ}$ compared to $0^{\circ}$ and $90^{\circ}$. Although the CFRP sheets have similar extension moduli in $0^{\circ}$ and $90^{\circ}$ direction, the bending modulus in $90^{\circ}$ is lower which leads to the shorter wavelength. The attenuation seems not to be affected by that, as can be seen in Fig. 12.

\section{Summary and Conclusion}

The subject of this work is the description and comparison of the vibration and damping behavior of hybrid carbon fiber reinforced plastics-elastomer-metal laminates (HyCEML) by several experimental setups over a wide frequency and temperature range. In addition, the vibration and damping behavior is modeled using existing numerical and analytical approaches. Depending on the experimental setups, typical temperature, frequency and mode dependent characteristics of the vibration and damping behavior of HyCEML could be carved out and weak points of the experimental characterization methods could be shown.

A general approach to measure the dynamic material behavior was performed by using dynamic mechanical analysis measurements. Here, the time temperature superposition principle of polymers was taken to describe the mechanical material properties, over a wide frequency and temperature range. This approach was used to characterize the viscoelastic behavior of the elastomer for numerical and analytical modeling, as well as for the hybrid material itself. The highest damping values were achieved in the glass transition region. However, at room temperature the glass transition is only reached at very high or very low frequencies, which are technically not relevant.

Experimental modal analysis with different specimen geometries and clamping conditions showed that the damping behavior strongly depends on the wavelength of the mode shape due to increasing transverse shear deformation for decreasing wavelengths. By comparing modal analysis and DMA under bending, it was shown that this effect is much stronger than the frequency-dependent viscoelastic material behavior under constant deformation. In addition, the support of the specimen can have a strong influence on the damping values and needs to be carefully chosen to reduce its influence. The analytical model based on the RKU equations with data of quasistatic tests and DMA on the neat materials can also predict the modal damping and vibration behavior quite well. The numerical model shows good agreement with the experimental and analytical approach, but it depicts the hybrid laminate too stiff, resulting in increased natural frequencies and damping. The differences between the analytical and numerical approach are attributed to the different modeling of the CFRP sheets. Nevertheless, the numerical model could be used to identify damping values, which were mistakenly measured too 
high in the experiments due to a negative influence of the specimen boundary conditions. In these cases, the deviations between experimental and numerical results on the panel geometry were then attributed to the foam based support of the specimen in the experimental modal analysis.

The generally high damping of the investigated HyCEML enabled the detection of running waves at relatively low frequencies, depending on the specimens' geometry. Due to the orthotropic CFRP layers, the wave propagation was affected as well with higher wave propagation velocities in the direction of the outermost fiber layers. Furthermore, the wave attenuation was affected due to different wavelengths and constraining layer stiffnesses. This behavior could also be depicted by the analytical RKU model in a modal approach.

It was shown that the different experimental setups can lead to comparable loss factors when the dependency of wavelength is taken into account. Thus, the comparison of subresonant damping in 3PB DMA and modal analysis was shown for such hybrid CLD laminate. The present study shows the resulting material behavior of inherent laminate damping in sub-resonant, resonant and super-resonant frequency regions. The neglecting of the CFRP and the aluminum contribution to the overall damping behavior proved to be valid for the present laminate configuration and the analytical modeling approach. For thinner or stiffer elastomer layers, however, this assumption must be validated. The presented numerical approach can be used to model the behavior of more complex mode shapes that cannot be depicted by the analytical approach and can also be applied to more complex structures for future investigations. Taking into account the nonlinear behavior of CFRP and elastomer in future studies might further improve the correlation between experiment and models. Yet, this has no influence on the main conclusions of our study, that the results from DMA and modal analysis lead to the same loss factors when the wavelength in both setups is matching and the wavelength of the bending waves shows much higher influence on the loss factor than the frequency dependent material behavior.

Acknowledgements This work is funded by the Deutsche Forschungsgemeinschaft (DFG, German Research Foundation) SPP1897 "Calm, Smooth, Smart - Novel approaches for influencing vibrations by means of deliberately introduced dissipation", project KA 4224/3-1,2 \& WE 4273/16-1,2 "HyCEML - Hybrid CFRP/ elastomer/metal laminates containing elastomeric interfaces for deliberate dissipation" (Karlsruhe Institute of Technology), project WA 1427/27-1,2 "Suppressing brake vibrations by deliberately introduced damping" (Technische Universität Berlin) and project KO 4333/1-1,2 "Lightweight structures with adaptive dynamic behavior through evanescent morphing" (Technische Universität Dresden). The authors would like to acknowledge Gummiwerk Kraiburg GmbH \& Co. KG for providing the elastomer.

Funding Open Access funding enabled and organized by Projekt DEAL.

Data Availability The datasets generated during and/or analysed during the current study are available from the corresponding author on reasonable request.

\section{Declarations}

Conflict of Interest The authors declare that they have no conflict of interest.

Open Access This article is licensed under a Creative Commons Attribution 4.0 International License, which permits use, sharing, adaptation, distribution and reproduction in any medium or format, as long as you give appropriate credit to the original author(s) and the source, provide a link to the Creative Commons licence, and indicate if changes were made. The images or other third party material in this article are included in the article's Creative Commons licence, unless indicated otherwise in a credit line to the material. If material is not included in the article's Creative Commons licence and your intended use is not permitted by statutory regulation or exceeds the permitted use, you will need to obtain permission directly from the copyright holder. To view a copy of this licence, visit http://creativecommons.org/licenses/by/4.0/. 


\section{References}

1. Kerwin, EM.: Damping of flexural waves by a constrained viscoelastic layer. J. Acoust. Soc. Am 31(7), 952962 (1959)

2. Rao, MD.: Recent applications of viscoelastic damping for noise control in automobiles and commercial airplanes. J. Sound Vib. 262(3), 457474 (2003). https://doi.org/10.1016/S0022-460X(03)00106-8

3. Fan, R., Meng, G., Yang, J., He, C.: Experimental study of the effect of viscoelastic damping materials on noise and vibration reduction within railway vehicles. J Sound Vib. 319(1-2), 5876 (2009) https:// doi.org/10.1016/j.jsv.2008.03.071

4. Amoroso, F., De Fenza, A. Monaco, E., Pecora, R., Lecce, L.: Experimental evaluation of vibro-acoustic behaviour of composite fuselage structures realized with embedded viscoelastic damping treatments, in: 18th International Congress on Sound and Vibration, Vol. 4 pp. 3197-3204. (2011)

5. Ross, D., Ungar, E.E., Kerwin, E.M.: Damping of Plate Flexural Vibrations byMeans of Viscoelastic Laminae, Structural Damping, ASME New York 49-87 (1959)

6. Nashif, A., Jones, D.I.G., Henderson. J.P.: Vibration damping Wiley Interscience New York (1985)

7. Alderliesten, R.: Fatigue and fracture of fibre metal laminates, Vol. 236 of Solid mechanicsand its applications, Springer (2017)

8. Stoll, M., Stemmer, F., Ilinzeer, S., Weidenmann, K.A.: Optimization of corrosiveproperties of carbon fiber reinforced aluminum laminates due to integration of an elastomer interlayer, in: Key Engineering Materials, Bremen, Germany, 742, pp. 287-293 (2017)

9. Bellini, C., Di Cocco, V., Iacoviello, F., Sorrentino, L.: Performance evaluationof CFRP/Al fibre metal laminates with different structural characteristics Composite Structures 225, 111117 (2019) https://doi. org/10.1016/j.compstruct.2019.111117

10. Kerwin, E.M., Ungar, E. E.: Requirements Imposed on Polymeric Materials by Structural Damping Applications, in: R.D. Corsaro, and L. H. Sperling (Ed.), Sound and vibration damping with polymers, Vol. 424 of ACS Symposium Series, American Chemical Society, Washington, DC, pp. 317-345 (1990). https://doi.org/10.1021/bk-1990-0424.ch017

11. Jones, D.I.G.: Handbook of Viscoelastic Vibration Damping John Wiley and Sons, LTD. Chichester (2001)

12. ASTM International, Standard Test Method for Measuring Vibration-Damping Properties of Materials, ASTM E756-05 (Reapproved 2010) (2010).

13. Ghiringhelli, G.L. Terraneo, M.: Analytically driven experimental characterization of damping in viscoelastic materials. Aerosp. Sci. Technol. 40, $75-85$ (2015) https://doi.org/10.1016/j.ast.2014.10.011

14. Wu, Q., Wang, M.: Study on the Dynamic Mechanical Properties of Viscoelastic Materials Based on Asymmetrical Sandwich Beams Applied Sciences 8(8), 1359 (2018) https://doi.org/10.3390/app8081359

15. Ozer, M.S., Koruk, H., Sanliturk, K.Y.: Testing non-magnetic materials using Oberst Beam Method utilising electromagnetic excitation. J. Sound Vib. 456, 104-118 (2019) https://doi.org/10.1016/j.jsv. 2019.05.029

16. Ferry, J.D.: Viscoelastic properties of polymers, John Wiley \& Sons, Inc., (1980)

17. Knapp, G., Oreski, G., Pinter, G.: Method to characterize the damping behavior of thin passively constrained layer laminates using dynamic mechanical analysis (DMA) in shear mode. Polym. Test. 42, 215-224 (2015) https://doi.org/10.1016/j.polymertesting.2015.01.011

18. Pan, L.J., Zhang, B.M.: A new method for the determination of damping in cocurred composite laminates with embedded viscoelastic layer J. Sound Vib. 319(3-5), 822-831 (2009) https://doi.org/10. 1016/j.jsv.2008.06.044

19. Martone, A., Antonucci, V., Zarrelli, M., Giordano, M.: A simplified approach to model damping behaviour of interleaved carbon fibre laminates Composites Part B: Engineering 97, 103-110 (2016) https://doi.org/10.1016/j.compositesb.2016.04.048

20. Graesser E.J. Wong, C.R.: The Relationship of Traditional Damping Measures for Materials with High Damping Capacity: A Review, in: V. K. Kinra and A. Wolfenden (Ed.), M3D: Mechanics and Mechanisms of Material Damping, ASTM STP 1169, Philadelphia, pp. 316-343 (1992)

21. Stoll, M., Sessner, V., Kramar, M., Technau, Weidenmann, K.A.: The effectof an elastomer interlayer thickness variation on the mechanical properties of Fiber-Metal Laminates. Compos. Struct. 219, 90-96 (2019) https://doi.org/10.1016/j.compstruct.2019.03.042

22. European Committee for Standardization, Plastics - Determination of tensile properties Part 5, EN ISO 527-5 (1997).

23. Luft- und Raumfahrt âĂŞ Faserverst Ãd'rkte Kunststoffe âĂŞ PrÃijfverfahren âĂŞ Bestimmung der Schubeigenschaften (Âśs 45Âř-Zugversuch), DIN EN 6031 (2016).

24. International Organization for Standardization, Rubber, vulcanized or thermoplastic -Determination of tensile stress-strain properties, ISO 37 (2017). 
25. International Organization for Standardization, Plastics - Determination of dynamic mechanical properties - Part 4: Tensile vibration - Non-resonance method, ISO 6721-4 (2008).

26. International Organization for Standardization, Plastics - Determination of dynamic mechanical properties - Part 7: Torsional vibration - Non-resonance method, ISO 6721-7 (1996).

27. Liebig, W. V., Jackstadt, A., Sessner, V., Weidenmann, K. A., Kärger, L. (2019). Frequency domain modelling of transversely isotropic viscoelastic fibre-reinforced plastics. Compos. Sci. Technol. 180, 101- 110. https://doi.org/10.1016/j.compscitech.2019.04.019

28. Timoshenko, S.P., Goodier, J. N.: Theory of Elasticity, 2nd Edition Edition, McGraw Hill Book Company, Inc., New York and London, (1951)

29. Williams, M.L., Landel, R.F., Ferry, JD., The Temperature Dependence of Relaxation Mechanisms in Amorphous Polymers and Other Glass-forming Liquids. J. Am. Chem. Soc. 77(14), 3701-3707 (1995)

30. Payne A.R.: Strainwork dependence of filler-loaded vulcanizates. J. Appl. Polym. Sci. 8(6), 26612686 (1964) https://doi.org/10.1002/app.1964.070080614

31. Chazeau, L., Brown, J.D., Yanyo Y.C., Sternstein, S.S.: Modulus recovery kinetics and other insights into the payne effect for filled elastomers. Polym. Compos. 21(2), 202222 (2000) https:// doi.org/10.1002/pc.10178

32. Mullins, L.: Softening of Rubber by Deformation Rubber Chemistry and Technology 42(1), 339362 (1969)

33. Sessner, V., Jackstadt, A., Liebig, W.V., Kärger L., Weidenmann, K.A.: Damping characterization of hybrid carbon fiber elastomer metal Laminates using experimental and numerical dynamic mechanical analysis. J. Compos. Sci. 3, 1-3 (2019) https://doi.org/10.3390/jcs3010003

34. Kunststoffe Bestimmung dynamisch-mechanischer Eigenschaften - Teil 3: Biegeschwingung; Resonanzkurven-Verfahren, DIN EN ISO 6721-3 (1996-12).

35. Chu, F..H., Wang, B.P.: Experimental determination of damping in materials andstructures, in: P. J. Torvik (Ed.), Damping Applications for Vibration Control, American Society of Mechanical Engineers, vol. 38, Chicago, pp. 113-122 (1980)

36. VDI Verein Deutscher Ingenieure e.V., Damping of materials and members (Experimental techniques for the determination of damping characteristics) - Part 5, VDI 3830-5 (2005)

37. Rao, D.K: Frequency and Loss Factors of Sandwich Beams under Various Boundary Conditions. J. Mech. Eng. Sci. 20(5), 271-282 (1978) https://doi.org/10.1243/JMES_JOUR_1978_020_047_02

38. Liebig, W. V., Sessner, V., Weidenmann, K.A.,Kärger, L.: Numerical andexperimental investigations of the damping behaviour of hybrid CFRP-elastomer-metal laminates Compos. Struct. 202, 1109-1113 (2018)

39. Jones. D.I.G.: On temperature-frequency analysis of polymer dynamic mechanical behaviour J Sound Vib. 140(1), 85-102 (1990)

40. VDI Verein Deutscher Ingenieure e.V., Modelling of vibrating systems, VDI 3843-1 (February 2018).

41. Gandhi, J.: Influence of Nonlinear Viscoelastic Material Characterization on Performance of Constrained Layer Damping Treatment AIAA Journal 39(5) 924-931 (2001). https://doi.org/10.2514/2. 1397

42. Paimushin, V.N., Firsov, V.A. Shishkin, V.M. Gazizullin R.K.: Vibration of the Platewith Integral Layer Damping: Experimental and Theoretical Studies, in: Gdoutos, E. Konsta-Gdoutos M.S.: (Eds.), Proceedings of the third International Conference on Theoretical, Applied and Experimental Mechanics, Vol. 16 of Structural Integrity, Springer, Cham, (2020). https://doi.org/10.1007/978-3030-47883-4_46

43. Caruthers, J.M., Cohen, R.E: Consequences of thermorheological complexity in viscoelastic materials. Rheologica Acta. 19(5), 606-613 (1980) https://doi.org/10.1007/BF01517514

44. Sessner, V., Weidenmann K.A.: Temperature Dependency of the Deformation Behavior of Hybrid CFRP/Elastomer/Metal Laminates under 3-Point Bending Loads Key Engineering Materials 809, 259265 (2019). https://doi.org/10.4028/www.scientific.net/KEM.809.259

45. Moreno, M.S.C., Gutiérrez, A.R., Vicente, J.L.M.: Different response under tensionand compression of unidirectional carbon fibre laminates in a three-point bending test Compos. Struct. 136,706-711 (2016) https://doi.org/10.1016/j.compstruct.2015.06.017

46. Cortés, F., Sarría, I.: Dynamic Analysis of Three-Layer Sandwich Beams with Thick Viscoelastic Damping Core for Finite Element Applications, Shock and Vibration 1-9 (2015) https://doi.org/10. 1155/2015/736256

47. Ewins, D.J.: Modal Testing: Theory, Practice and Application, Research Studies PressLtd., John Wiley \& Sons, Inc (2000)

48. Carne, T.G. Griffith, T.D. Casis, M. E.: Support conditions for experimental modal analysis. Sound and Vibration 41(5), 10-16 (2007) 
49. Mallareddy T.T., Schneider, S. Blaschke P.: Advanced Hammer Excitation Technique for Impact Modal Testing on Lightweight Materials Using Scalable Automatic Modal Hammer, in: M. Mains, B. J. Dilworth (Eds.), Topics in Modal Analysis \& Testing, Volume 9, Springer International Publishing, Cham, pp. 211-216 (2019)

50. Schneider S., Mallareddy T.T., Alarcón D.J., Kamenzky R., Blaschke P., Experimental Modal Analysis of Structures with Conventional Versus Contact-Free Suspension., in: N. Dervilis (Ed.), Special Topics in Structural Dynamics, Volume 5. Conference Proceedings of the Society for Experimental Mechanics Ser, Cham, 2019.

51. O. Dossing, Structural Testing Part II: Modal Analysis and Simulation, Naerum: Bruel \&Kjaer, 1988.

52. Manconi, E., Mace, B.R.: Estimation of the loss factor of viscoelastic laminated panels from finite element analysis. J. Sound Vib. 329(19), 3928-3939 (2010). https://doi.org/10.1016/j.jsv.2010.04.014

53. Liao, F.S., Hsu, T.J., Su, A.C.: Vibration Damping of Interleaved Carbon FiberEpoxy Composite Beams. J Compos Mater. 28(18), 1840-1854 (1994) https://doi.org/10.1177/002199839402801806

Publisher's Note Springer Nature remains neutral with regard to jurisdictional claims in published maps and institutional affiliations.

\section{Authors and Affiliations}

\section{Vincent Sessner ${ }^{1} \cdot$ Wilfried V. Liebig ${ }^{1}$ (D) Alexander Jackstadt ${ }^{2} \cdot$ Dominik Schmid $^{3}$. Tom Ehrig ${ }^{4} \cdot$ Klaudiusz Holeczek $^{4}$ - Nils Gräbner ${ }^{3}$ - Pawel Kostka ${ }^{4}$. Utz von Wagner ${ }^{3}$. Kay A. Weidenmann ${ }^{5}$. Luise Kärger ${ }^{2}$}

Vincent Sessner

vincent.sessner@kit.edu

Alexander Jackstadt

alexander.jackstadt@kit.edu

Dominik Schmid

dominik.schmid@tu-berlin.de

Tom Ehrig

tom.ehrig@tu-dresden.de

Klaudiusz Holeczek

klaudiusz.holeczek@tu-dresden.de

Nils Gräbner

nils.graebner@tu-berlin.de

Pawel Kostka

pawel.kostka@tu-dresden.de

Utz von Wagner

utz.vonwagner@tu-berlin.de

Kay A. Weidenmann

kay.weidenmann@mrm.uni-augsburg.de

Luise Kärger

luise.kaerger@kit.edu

1 Institute for Applied Materials (IAM), Hybrid and Lightweight Materials, Karlsruhe Institute of Technology (KIT), Engelbert-Arnold-Str. 4, D-76131 Karlsruhe, Germany

2 Institute of Vehicle System Technology (FAST) Lightweight Technology, Karlsruhe Institute of Technology (KIT), Rintheimer Querallee 2, D-76131 Karlsruhe, Germany

3 Department of Applied Mechanics, Chair of Mechatronics and Machine Dynamics (MMD), Technische Universität Berlin (TUB), Einsteinufer 5, 10587 Berlin, Germany 
4 Institute of Lightweight Engineering and Polymer Technology (ILK), Technische Universität Dresden (TUD), Holbeinstr. 3, 01307 Dresden, Germany

5 Institute of Materials Resource Management (MRM), University of Augsburg (UA), Universitaetsstr. 1, 86159 Augsburg, Germany 